\title{
Process-Based Identification of Critical Factors for Residual Value Risk in China's Highway PPP Projects
}

\author{
Chuanjun Zheng $\mathbb{D}^{1},{ }^{1}$ Jingfeng Yuan $\mathbb{D D}^{1}{ }^{1}$ Lingzhi Li ${ }^{1},{ }^{2}$ and Mirosław J. Skibniewski ${ }^{3,4,5}$ \\ ${ }^{1}$ Department of Construction and Real Estate, School of Civil Engineering, Southeast University, Nanjing 211189, China \\ ${ }^{2}$ School of Civil Engineering, Nanjing Tech University, Nanjing 211816, China \\ ${ }^{3}$ Department of Civil and Environmental Engineering, University of Maryland, College Park, MD 20742, USA \\ ${ }^{4}$ Institute for Theoretical and Applied Informatics, Polish Academy of Sciences, Gliwice 44100, Poland \\ ${ }^{5}$ Department of Construction Engineering, Chaoyang University of Technology, Taichung 41349, Taiwan \\ Correspondence should be addressed to Jingfeng Yuan; jingfeng-yuan@seu.edu.cn
}

Received 6 December 2018; Revised 4 March 2019; Accepted 3 April 2019; Published 9 May 2019

Academic Editor: Flavio Stochino

Copyright (c) 2019 Chuanjun Zheng et al. This is an open access article distributed under the Creative Commons Attribution License, which permits unrestricted use, distribution, and reproduction in any medium, provided the original work is properly cited.

\begin{abstract}
Although the Chinese government at all levels has increasingly embraced Public-Private Partnership (PPP) as their preferred approach to deliver large-scale infrastructure since 2014, residual value risk (RVR) has been ignored in PPP practice. To systematically explore the critical risk factors (CRFs) responsible for measuring RVR in highway PPP projects, this paper proposes and refines a conceptual model composed of two risk dimensions (four risk categories) and 29 indicators through process-based viewpoint. Through literature review and expert interview, a structured questionnaire was developed to collect responses with rich working experience in construction industry or highway PPP projects. The refined measurement model with 21 CRFs was validated through mean value analysis (MVA) and confirmatory factor analysis (CFA) performed by SPSS 23.0 and AMOS 23.0, respectively. The findings indicate that 21 CRFs are significant in influencing RVR of highway PPP projects. Moreover, RVR from system dimension is mainly concentrating on institutional environment, macroeconomy, and relationship aspects, whereas financing in preconstruction, quality in construction, and market demand in operation are the most significant CRFs in nonsystem dimension. Furthermore, there is an accumulative exposure of RVR during the project process, especially in preconstruction and operation. This paper sheds light on the significance of lifecycle management on RVR and provides a practical approach for measuring RVR and implementing sustainable practice in highway or other transportation PPP projects.
\end{abstract}

\section{Introduction}

Over the past few decades, governments across the world have increasingly adopted Public-Private Partnership (PPP) to deliver large-scale public infrastructure and service, especially in the provision of transportation infrastructure [1-3]. On November 2017, the Undersecretary of Ministry of Finance Shi Yaobin [4] pointed out that China had become the largest and most influential PPP market around the world since 2014 because it has increasingly institutionalized transformation strategy as well as public procurement method in providing infrastructure products and service. Traditionally, transportation is the typical sector to receive private finance in PPP practice $[5,6]$. There are 516 transportation PPP projects among the third batch of pilot PPP projects in China, accounting for $43 \%$ of the total investment (1.1 trillion) and $12 \%$ of the total project number (516), respectively [7]. Highway is the typical transportation infrastructure to improve productivity and competitiveness for economic development. China has launched the overall planning for state highway trunk line since 1990s with enormous investment scale annually [8]. Faced with challenges such as high fiscal pressures, technology complexity, and growing traffic demands, the government seeks for private investments and, meanwhile, reallocates responsibilities of finance, design, construction, operation, and maintenance by PPP for providing transportation service effectively and efficiently $[2,9]$. Therefore, the 
responsibilities to provide transport infrastructure in China have been steadily moving away from the realm of government to that of the private sector through PPP since 1990s [2, 9]. Driven by the new upsurge of PPP since 2014, highway PPP projects have witnessed an obvious increase because of rapid development of urbanization in China.

However, as an emerging PPP market compared to the mature market such as UK and Australia, China is weak in coherent institutional environment and expertise of project lifecycle assessment for PPP [10]. The evolution process of PPP in China reveals that political, cultural, and institutional context have strongly influenced the performance of PPP $[6,9,11]$. Unlike the traditional delivery methods of letting contract for the separated tasks that are needed to create, operate, and maintain a road, PPP requires the private sectors take responsibilities for construction, operation, and maintenance with effective risk transfer and incentives for reducing costs and improving quality during the concession period [2,5]. During the transition from a short-term contract period in traditional projects ( $\leq 5$ years) to a long-term contract period in PPP projects (20-30 years) [12], the experience with infrastructure PPP internationally have demonstrated many problems and partnership failures. Related problems or failures could include value for money (VfM) not achieved, concession cancelled, concession tender cancelled, project nationalization, project halted, and contract suspension because of long-term uncertainty and divergent objectives among project stakeholders [13, 14]. Currently, there is a lack of qualified knowledge and ability on VfM assessment, lifecycle management/supervision, mature contract arrangement, and clear division of responsibility within relevant government agencies in China $[6,10]$. Accordingly, external environment, internal project characteristics, and partnership-related factors would influence the project success and final performance of transportation PPP [3]. Considering highway PPP projects require heavy initial investment, long-term operation, and market support, the above challenges bring a serious problem on whether infrastructure facility can meet the expected performance defined in agreement or support sustainable operation upon earlier termination or concession expiration. Therefore, risk management and project performance should be highly addressed in order to improve the sustainable development of highway PPP projects.

To integrate risk management and project performance in highway PPP projects, RVR was introduced in this study. RVR in PPP can be defined as "the risk that on the expiry or earlier termination of the services contract, the asset (tangible or intangible) is not in accordance with the value originally estimated by the government and determined in the contract, at which the private party agreed to transfer PPP projects back" [15]. As presented by Yuan et al. [16], many problems such as downfall performance, functional problems, decreasing profitability, difficulty in refinance, deterioration of maintainability, decline in operability, and failure of sustainability occurring in the full project cycle are in relationship with RVR management of PPP. Without sufficient emphasis on RVR, the public and private sectors would suffer huge loss of residual value (RV) and compensation from government, respectively, which could greatly influence the project's success as well as public welfare. Therefore, RVR has been viewed as a critical issue when infrastructure projects are reverted to the public sector [17-19]. Highway PPP projects with a typical concession period from 20 to 30 years under the operation of private sector, whereas the governance of transportation PPP projects has been reported as weak and ineffective in many cases with expensive costs in risk transfer [5, 20, 21]. Due to complex organization structure and financial arrangement in the long-term concession period, any external and internal risk factors would impair the expected performance of infrastructure projects defined in the PPP agreements. Thus, RVR may rise when the project is to be transferred to the host government upon concession expiration or earlier termination because of unrealized value, as presented by HM Treasury of UK [22] and Comptroller and Auditor General of India [23].

Although prior study has defined the underlying dimensions of RVR in PPP generally [16], verified the importance of RVR management through case study in China [15], and explored RVR in value-based perspective [24], few studies have explored the CRFs for RVR and their impact on RVR management in highway PPP projects. Moreover, detailed and careful identification of CRFs that can heavily influence the tangible and intangible RV of highway PPP projects should be further implemented based on the process-based viewpoint, which adapt to the value chain from development to facility management in highway PPP projects. Meanwhile, the identified factors should dynamically reflect the change of RV in highway PPP projects. Therefore, this paper aimed to identify the CRFs for measuring RVR in highway PPP projects from the process-based perspective, which could further promote the in-depth understanding of RVR and improve RVR management for project participators and sustainable development of PPP. The following section presents a comprehensive literature review of relevant studies, followed by a presentation of the research methodology used in this paper, and establishment of the proposed conceptual model of CRFs for RVR management in highway PPP projects to illustrate theoretical relationships between CRFs and two dimensions (four categories). After then, a nationwide survey aimed at investigating CRFs of RVR in China's highway PPP projects is described, followed by survey evaluation, construct validity, and confirmatory factor analysis (CFA). In data analysis, mean value analysis (MVA) and CFA were used to explore the CRFs and clarify their relationships in highway PPP projects.

\section{Literature Review}

2.1. Recent Development of PPP in China. Considering that PPP is more advantageous than traditional delivery in providing infrastructure for future development, a substantial body of knowledge on PPP has been generated across the world by a broad spectrum of practitioners from government, the private sector, international development institutions, academia, and expert advisors, especially the 
good practices on infrastructure and PPP policies and implementation with sustainable goals globally [25]. Due to PPP upsurge promoted by the government from top to down, China has not only become the important research center of PPP globally [26], but also the largest emerging PPP market in Asia-Pacific [10]. Correspondingly, the pilot PPP projects have increasing application in thirty provinces and eighteen industry sectors in China, ranging from economic infrastructure to social infrastructure [7]. Among them, highway PPP projects occupy a key position in transportation PPP projects because it is the PPP sector with high maturity in China $[6,7]$.

In PPP, both the public and private participators should bring more values such as the best available skills, knowledge and resources and transfer them to the arrangement to strive for VfM in providing public infrastructure services [8]. However, constrained by the institutional environment (e.g., command economy, highly centralization, and discrete administrative structure) $[6,9]$ and immature PPP market in China [10], three critical problems still remain with PPP success and performance. Firstly, the private sector's focus on short-term financial return on investments is usually assumed to be at odds with the long-term perspective needed to realize sustainability objectives for public welfare even though the public and private sectors have a common goal on completing the project successfully $[14,27]$. Thus, VfM may fail to be achieved because of conflicts of interest among project stakeholders during the long-term concession period. Secondly, traffic demand-determined ex ante cannot cope with the problems related to traffic volume with long-term uncertainty in transportation PPP projects [28, 29], especially the unjustified optimism bias regarding demand forecasts $[1,29]$. Meanwhile, there is a failure path among improper demand forecasting, low traffic demand, less revenue generation, and concessionaire insolvency for private sector [13] because revenue risk is beyond its full control. Thirdly, public sector would sign unbalanced concession agreements by bearing too many risks due to lack of experience, thirst for private investment, and emphasis on short-term benefit $[6,9,10,27,30]$. Under strategic vision, future uncertainty from macrolevel, mesolevel, and microlevel should be stressed for project success and final performance in transportation PPP projects. As for highway PPP projects, this is the case because it is the typical transportation infrastructure through user-pay in developing countries [25].

Although the institutional environment is far more mature, China is on its way to establishing a strong framework for PPP in line with international best practice. Unlike the emphasis on private finance for infrastructure projects in the initial stage of PPP in 1990s, public welfare and project performance is on the top priority for PPP in renewed policy framework since 2014. Meanwhile, the central government of China has facilitated the process of PPP projects, attempting to make a transition from user-pay PPP to government-pay PPP system with the aim of facilitating infrastructure investment and government transformation [31, 32]. Thus, the Chinese government would be more concerned about the effectiveness and efficiency of PPP project transfer [33], which means that RVR in China will receive increasing importance. Many prior studies point out that disputes and losses related to RV and the transferring of PPP projects can be attributed to policy and law change, design problems, poor maintenance of the assets, completion delay, high costs and price, and public opposition [34-36]. The reason can be concluded that the public sector cannot obtain the return in the desired condition $[15,16,37]$. With the progress of pilot PPP projects, both the public and private sectors should attach more importance on sustainable development of PPP practice.

2.2. Risk Management and RVR in PPP. As for PPP research globally, emerging trends are found in risk allocation, performance evaluation, renegotiation of concession contracts, real option evaluation, and contract management [26]. With the implementation of PPP projects, sustainable PPP has become the focus among research community. Many prior studies have made great efforts on transportation PPP projects, including road, highway, high speed rail, tunnel, etc. [14, 38, 39]. Risk management is the focus in PPP related studies, which cover a range of specific fields such as risk allocation $[19,37,38,40]$, government-related risk [41-43], and CRFs [44-47]. Among these studies, risk allocation among project participators and identification and evaluation of risk factors are the two main themes [48]. However, there is a lack of understanding of PPP risks with value-based perspective and sustainable consideration.

RVRs offer a new perspective to understand risks associated with RV and have been identified as critical risk that will have strong influences on the RV of initial bids $[17,18,49,50]$. However, the project participators may ignore this potential problem due to the accumulative effects on the long-term concession period, which could make the RVR and risk burst upon expiration or termination. It is more typical in highway PPP projects because they have a repay period of 20 years generally with dynamic uncertainty [5]. Maintenance performance and residual life span as contractually required may be imposed when handing back the highway to the local authority [51]. If RVR cannot be well managed, long-term indebtedness with high costs, poor services with public discontentment, and contract renegotiation in favor of private provider could occur during the long-term concession period. Demirag et al. [52] believed that RVR was the most important in the context of PPP because it was more likely to affect the goal of off-balance sheet project treatment. Thus, suitable management of RVR would be of tremendous value for better maintenance, easier transfer of PPP projects, improvement of ongoing management, and sustainable development of infrastructure [18].

Traditional risk management framework provides useful lessons for RVR management, which usually include risk identification, risk evaluation, risk allocation, and risk control. Some studies have focused on RVR management of PPP. As presented by Algarni et al. [53], RVR could occur when facility assets have been suffering years of neglect, overuse, deferred maintenance, and delayed repair, which would harm the sustainable development of infrastructure. This view also received the support from $\mathrm{Xu}$ et al. [35] and 
Chan et al. [37]. Moreover, many official documents have identified related risk factor of RVR, such as construction costs, service demands, operation costs, and technological change [23, 34]. Allocation of RVR between public and private has also been discussed [40, 54, 55]. An RVR treatment method deliberated whether RVR could be dealt with by simply writing off the asset completely over the life of the contract. To support RVR management, risk identification of CRFs is the foundation, which is similar with the CRFs identification in the sectors of water supply projects [56], comparison of risk factors among water and wastewater, power and energy, transportation projects [44], waste-to-energy projects [47], and CRFs of water projects [46]. These studies provide an in-depth cognition of RVR as well as reference for exploring CRFs of RVR in highway PPP projects.

However, CRFs, which can be used as measures to reveal the potential presence, level, or trend of a risk, have not been developed for RVR in highway PPP projects. They can indicate the specific scope, exposure level, and trend of a risk for RV. Thus, CRFs can provide valuable information about a risk situation that may or may not exist and serve as a signal for further action [57]. When being implemented properly, CRFs can provide significant insights into the changes in the risk profile and bring additional strategic and operational value [58-60]. CRFs have been adopted widely in the fields of financing, enterprise management, banking, and e-business $[61,62]$. Under the context of RVR in highway PPP projects, CRFs can be used as a tool to predict the change of RVR and allow for proactive intervention before the project is transferred $[15,16]$. Therefore, a significant work of this paper is to develop CRFs for RVR by analyzing the events that could affect the RV of highway PPP projects in China and explore its roots of underlying causes.

2.3. Knowledge Gap. Based on extensive review of prior research, the following knowledge gaps can be identified in the two aspects. Firstly, the lack of effective RVR management leads to serious dispute and public discontent because of low RV left at the end of concession period or when being transferred in advance. Few studies have attached enough importance on the cumulative effect of RVR in PPP projects, and process-based view of RVR can make further cognition of RVR in PPP. Secondly, although prior studies have defined the general framework of RVR in PPP, few studies have observed the differences of different sectors among PPP projects. Therefore, CRFs of RVR in highway PPP projects will promote RVR management in this typical user-pay PPP projects. This paper attempts to fill these knowledge gaps, with emphasis on process-based perspective and highway PPP projects. The identified CRFs would be very useful to measure RVR of highway PPP projects and provide important reference for RVR management in other types of PPP projects.

\section{Research Methods}

3.1. Empirical Study Design. The key research goal of this study is to verify the proposed conceptual model in measuring RVR and find the CRFs of RVR in highway PPP projects. To achieve this research goal, a comprehensive research method was applied in this study. The whole research flow is shown in Figure 1.

Firstly, an extensive literature review was conducted, which focused on PPP development in China as well as global risk management and RVR researches in PPP. These related researches provide a clear picture of current situation of RVR and risk management in PPP literature. Secondly, a conceptual model of RVR in highway PPP projects was proposed in process-based viewpoint. Meanwhile, the initial factor system of RVR, including RVR dimensions, categories, and factors in highway PPP projects was developed through literature review and content analysis. Thirdly, a structured questionnaire was developed to investigate the respondents' views on the significance of factors of RVR in highway PPP projects. Fourthly, MVA and CFA are used to validate the measurement model and identify the CRFs of RVR in highway PPP projects by SPSS 23.0 and AMOS 23.0 respectively. The significance of the initial risk factors of RVR was first assessed by their mean scores on the 5-point Likert scale. This simple scale enables easy interpretation of survey results by policy makers, which has been widely used in construction management research [38, 63-65]. Moreover, the applicability of CFA in this study lies on the following aspects. Firstly, the underlying assumption of the MVA, which compares the relative importance of each factor, evaluates each factor independently without considering the covariance. Considering that factors identified by prior studies may be empirically dependent on each other, CFA was used to address the potential drawback of MVA because the loading coefficient obtained for each factor that contributes to the variance explained in the categorical constructs [38]. Secondly, CFA is the measurement model to depict the pattern of observed variables for those latent constructs in the hypothesized model [66], which were mainly used for validation of existing or newly developed frameworks [67]. It is consistent with the research characteristics under study. Thirdly, RVR for PPP has been presented by the author's prior study and accepted among research community. CFA is just right because it is theorydriven [66]. Then, the insignificant factors were removed from the initial factor system based on the two-dimensional important analysis (mean value from MVA and loading coefficient from CFA) [38], with refined CRFs for RVR in highway PPP project. Lastly, the survey results were analyzed and strategic implications of identified CRFs were discussed, aiming to detect, explain, and improve the understanding of RVR in highway PPP and promote RVR management for sustainable PPP in China.

3.2. Data Collection. The questionnaire consists of two sections with a total of 29 factors. The first section collected background information for the respondents and general issues about PPP, e.g., working units, professional fields, and working experience in highway PPP projects or in other infrastructure projects. The second section aims to 


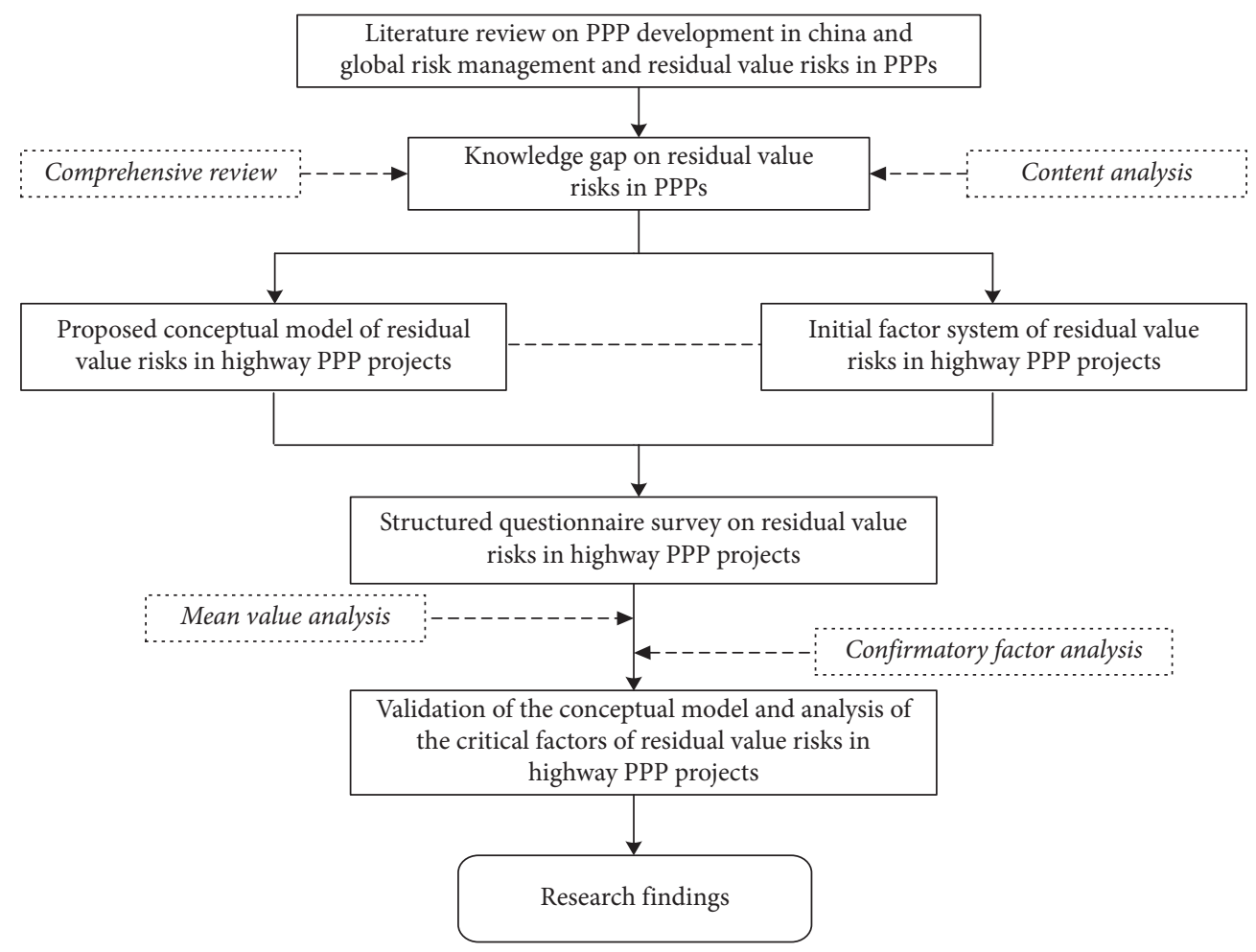

Figure 1: Research flow in this paper.

investigate the importance of the 29 factors (Table 1), which are divided into two dimensions (system and nonsystem) and four categories for measuring RVR in highway PPP projects. In this section, each latent variable is measured using a set of associated indicators, which were selected based on the extensive literature review. The target respondents were asked to provide their personal perceptions on the importance of indicators, using a five-point Likert scale (1-not important, 2-less important, 3-important, 4more important, and 5-most important). Additionally, a comment box is given at the end of the questionnaire to allow further comments (e.g., additional risk factors of RVR in highway PPP projects) by the respondents. The questionnaire draft was reviewed by 9 experts in China. Among them, 3 researchers are from Tsinghua University, Tianjin University, and Dalian University of Technology respectively. As indicated by co-author analysis of global PPP research by Song et al. [26], these three universities have significant research power in the field of PPP; 3 senior professionals are from China State Construction Engineering Corporation limited, China Communications Construction Company Limited, and China Railway Construction Corporation Limited. These three companies are not only the largest contractors in China but also the top 250 global contractors assessed by Engineering NewsRecord in 2018 [78]; and 3 government officials are from relevant government agencies, including Development and Reform Commission, Department of Finance, and Department of Transport in Nanjing and Jiangsu Province. All of the target experts have enough experiences in transportation PPP projects, aiming to improve the content and avoid misunderstandings.
The formal survey sampled construction professionals and experts at the annual conference of The Architectural Society of China-Construction Management Research Sector (ASC-CMRS) in July 15-18, 2016. This is a grand meeting of the construction management industry. There are also subforums on PPP projects, attracting a large number of people from academic and practical fields. Target respondents were selected based on their direct hands-on involvement in transportation PPP projects and other type of PPP projects. Convenience sampling was used instead of random sampling because of no existing database of PPP researcher and practitioners in China or complete list of the participators in the mentioned conference, and this sampling method was also used in the similar researches conducted by Chan et al. [64], $\mathrm{Ke}$ et al. [65], and Li et al. [63]. Moreover, our research team has limited connections with the potential respondents in the conference. Since the survey cannot bring interferences to the conferences, the questionnaire survey can only be implemented during the rest time. Considering that some of these target respondents would have colleagues and personal connections that would be beneficial to reach the right respondents, some of the respondents were dispatched more than one copies of the survey form. A total of 320 questionnaires was sent out at the conference site, with 98 valid questionnaires $(30.6 \%$ return rate) received finally.

\section{Conceptual Model of CRFs in Measuring RVR in Highway PPP Projects}

4.1. Conceptual Model of RVR in Highway PPP Projects. Although six dimensions of internal risk factors have been redefined for PPP generally [16], there is a lack of focus on 
TABLE 1: Summary of the initial factor system of RVR in highway PPP projects.

\begin{tabular}{|c|c|c|}
\hline Category & Risk factors & Remark/description \\
\hline \multirow{12}{*}{ System } & F1 law and policy change & $\begin{array}{l}\text { The institutional framework is an indicator of a country's capacity to deal with the } \\
\text { complexities of PPP procurement while minimizing institutional risk and delays [10] }\end{array}$ \\
\hline & F2 tax increase & $\begin{array}{l}\text { Tax increase lead to compressed profit space and increased financial pressure in operation } \\
{[68]}\end{array}$ \\
\hline & $\begin{array}{l}\text { F3 government } \\
\text { intervention }\end{array}$ & Government intervention was a primary cause of failure recorded in different sectors [44] \\
\hline & F4 interest rate fluctuation & $\begin{array}{l}\text { Interest rate fluctuation is related to pricing and cash flow in highway PPP projects, and } \\
\text { high interest debt may cause the failure of VfM }[8,20]\end{array}$ \\
\hline & F5 foreign exchange & $\begin{array}{c}\text { Foreign exchange may bring exchange loss and fiscal pressure involved with foreign } \\
\text { investment and offshore purchase [69] }\end{array}$ \\
\hline & F6 inflation risk & $\begin{array}{l}\text { Inflation is always related with economy concession, which may reduce the willingness to } \\
\text { pay and increase the total investment }[8,70]\end{array}$ \\
\hline & F7 public opposition & $\begin{array}{l}\text { Public opposition can create massive problems for project developers, including outright } \\
\text { cancellation of the PPP project [13] }\end{array}$ \\
\hline & F8 credit risk & $\begin{array}{l}\text { Public credit was the severe risk of PPP in different sector [44], and perfect credit system } \\
\text { can improve the efficiency of PPP implementation }\end{array}$ \\
\hline & F9 force majeure & $\begin{array}{l}\text { Force majeure risks represent a risk category that requires delicate management as it may } \\
\text { cause tremendous losses to the private party and RV of PPP projects [71] }\end{array}$ \\
\hline & F10 contract risk & $\begin{array}{l}\text { Demand risk allocation and coordination between the government and private firms by } \\
\text { rigid contract are hard to fulfill the BOT concession contracts completely because of traffic } \\
\text { demand uncertainty [28] }\end{array}$ \\
\hline & F11 organizational risk & $\begin{array}{l}\text { Building PPP is an interactive process that requires close and intensive communication, } \\
\text { negotiation, and collaboration between the public and private sectors to avoid the losses of } \\
\text { RV in PPP [3] }\end{array}$ \\
\hline & F12 stakeholder risk & $\begin{array}{l}\text { Many stakeholder events in PPP are social in nature, and internally oriented response to } \\
\text { them result in dissatisfactory outcomes [72] }\end{array}$ \\
\hline
\end{tabular}

Nonsystem

F13 land acquisition

Failure to land acquisition timely may cause slow and hindered project progress and ultimately end either in the cancellation of the concession or in nationalization of the project [13]

F14 delayed approval

Preconstruction F15 financing risk

F16 design defects or delay

Delayed approvals and actions by public sector officials would slow and hindered project progress, with connection with project nationalization [13]

Financial strategy for the project company directly affects the amount of capital expenditures that take the biggest part in the cost structure of the project [73]

An optimized design can facilitate lifecycle cost cutting by constructability, maintenance, and operationability to improve the RV of PPP projects [24]

F17 technical risk

Unproved technology or inadequate technical feasibility assessment adopted may trigger technical error, project halted and failure to achieve desired functions [13] F18 cost overrun risk number of project characteristics such as planned project duration, length, engineer's cost estimate, and number of work activities [74]

Construction F19 schedule delay

F20 resource availability

F21 quality risk

F22 operation costs

F23 quality of service

F24 maintenance costs

F25 accident in maintenance

Operation

F26 market demand

F27 horizontal competition

F28 change in toll

F29 environment risk

Project that cannot reach the pre-determined production target or cannot be launched into production as scheduled will result in inadequate cash flow during operation period [75] Resource availability is an critical success factors in PPP [3], and optimized resources utilization can improve the implementation efficiency and better offers for the public [76] Poor quality works will cause the loss of customer trust and legal proceedings with private sector partner [20]

Any reduce on operation cost mean an increase for profit of the private sector, but lowquality operation may affect traffic demand [75]

Quality of service may affect the customer trust and traffic demand [20]

Pavement deterioration can be slowed down by maintenance, and high maintenance cost may increase the difficulty of profitability [8]

Accidents in maintenance result in the disruption of services, which directly affect the public users and then the public agency [5]

Demand depends on a range of interrelated and dynamic factors such as the demographic and economic conditions, and demand risk faced during the operation stage has considerably limited the efficiency of road delivery [77]

Competing or parallel facilities is related to demand risk, with influence on profitability of transportation PPP projects [77]

Change in toll leads to variation of traffic flow and thus to revenue generation [70]

Environmental sustainability is an important focus for the public because remedy of environmental may be even worse than the disease [27] 
exploring specific risk factors of external environment and project stages of PPP. This study concentrates on identifying the CRFs of RVR in highway PPP projects with systematic and process-based viewpoint, which is suitable for long-term performance orientation in highway PPP projects.

In prior study, risk factors of PPP have been defined from different perspectives. Ke et al. [40] divided risks in PPP into government-related, private-related, and shared risks accompanying with macro, meso, and microgroups. Shen et al. [43] classified risks in PPP into project-related, government-related, client-related, design-related, contractor-related, consultant-related, and market-related risks. Xu et al. [35] identified six critical risk groups by factor analysis, including macroeconomic risk, construction and operation risk, government maturity risk, market environment risk, economic viability risk, and government intervention. As concluded by Cheung and Chan [44], all these identified risk factors are similar. In order to reveal the dynamic and procedural characteristics of RVR in highway PPP, all the CRFs can be attributed to two dimensions-system and nonsystem risks in a different perspective. System risks refer to those that are related to external impacts or cannot be controlled by the concessionaire during the concession period [79], including political risk, law risk, economic risk, and so on. In contrast, nonsystem risks are those risks related to the project activities within organization network formed by contract, which would vary according to internal project characteristics. Furthermore, nonsystem risks are divided into three successive stages based on the authors' prior work [16], including preconstruction, construction, and operation. For PPP projects, the conducive regulatory frameworks and effective institutions by government can improve their capacity to select, design, deliver, and manage projects and to develop local finance facilities, which provide an environment to attract private investors and achieve best value for PPP by proper regulation [30]. Thus, RV would inevitably be influenced by the uncontrollable external environment and systematic impacts $[41,80]$. In comparison, nonsystem risks will be easy to control with resources of project participators as long as they conduct good teamwork and collaboration during the project processes. Moreover, all system risks would affect the nonsystem risks by combining the specific risks in different stages as well as the change of $\mathrm{RV}$ in highway PPP projects. Based on the related researches $[57,58]$, each risk factor can be measured through a series of specific indicators. Thus, CRFs can be explored with the guidance of the proposed conceptual model consisting of all risk factors of RVR in highway PPP projects.

As shown in Figure 2, the conceptual model of RVR in highway PPP projects can clearly illustrate how RVRs are generated from external and internal environment in different levels as well as the accumulative effect of RVR on the change of RV in the concession period of highway PPP projects. The system dimension of RVR in highway PPP projects mainly include political, legal, economic, and social risk, which affect the whole progress of RVR in highway PPP projects. The nonsystem dimension of RVR in highway PPP projects are identified in processed-based perspective to explore specific indicators, which are related with project activities in different stages. CRFs of RVR in highway PPP projects may present the key ratios that management tracks as indicators of evolving RVR in highway PPP projects, which provide guidance for actions in practice.

\subsection{Factor System of Measuring RVR in Highway PPP Projects.} Based on the conceptual framework mentioned above, the initial factor system of RVR in highway PPP projects was developed through literature review and content analysis, including 29 factors (two dimensions and four categories) for measurement. The specific risk factors as well as corresponding interpretations related to RVR in highway PPP projects are compiled in Table 1, followed by the analyses from the two dimensions.

4.2.1. Factors of RVR in System Dimension. The risk factors of system dimension involve with external and systematical risks, which covers the risk factors from F1 to F12. Since PPP contracts are generally "regulatory contracts" signed by a public authority and a private party [1], it inevitably needs the political support to strengthen cooperation confidence and contract enforcement during the long-term concession period. As an innovative method to replace the government's responsibility in providing transportation service directly, highway PPP projects always require revenue sources or rights to be granted to the contractor to support its capital, operating, financing, and transaction expenses and to provide a return by user-pay. Therefore, the project viability is closely related with macroeconomy and the social willing-to-pay. In project planning, highway infrastructure projects closely involve external stakeholders such as citizens and public permitting organizations, and building a supportive environment and ensuring transparency are helpful for project implementation [30, 77]. Moreover, force majeure and organizational risk are usually shared by the public and private sectors [40]. Although they are out of the control of the project participators, the two risks can exert systematic or external influence on highway PPP projects. In PPP practice, partnerships require stable and trusted systems of enforceable laws to deal with contracts, disputes, liabilities, and property rights [81] and clear legislative frameworks specifying their roles, their relationships, and areas of cooperative PPP [82]. PPP contract defines the basis of PPP implementation between the public and private sectors, and vague contract description often leads to legal proceedings and failures to VfM [13]. Overall, the systematic risk factors determine the external environment as well as the basis for highway PPP. Therefore, they have a significant influence on economic efficiency and business environment for initiative and implementation in the full project cycle of highway PPP projects.

4.2.2. Factors of RVR in Nonsystem Dimension. The nonsystem dimension of RVR in highway PPP projects consists of three consecutive stages as mentioned before, and each stage is comprised of the underlying factors associated with 


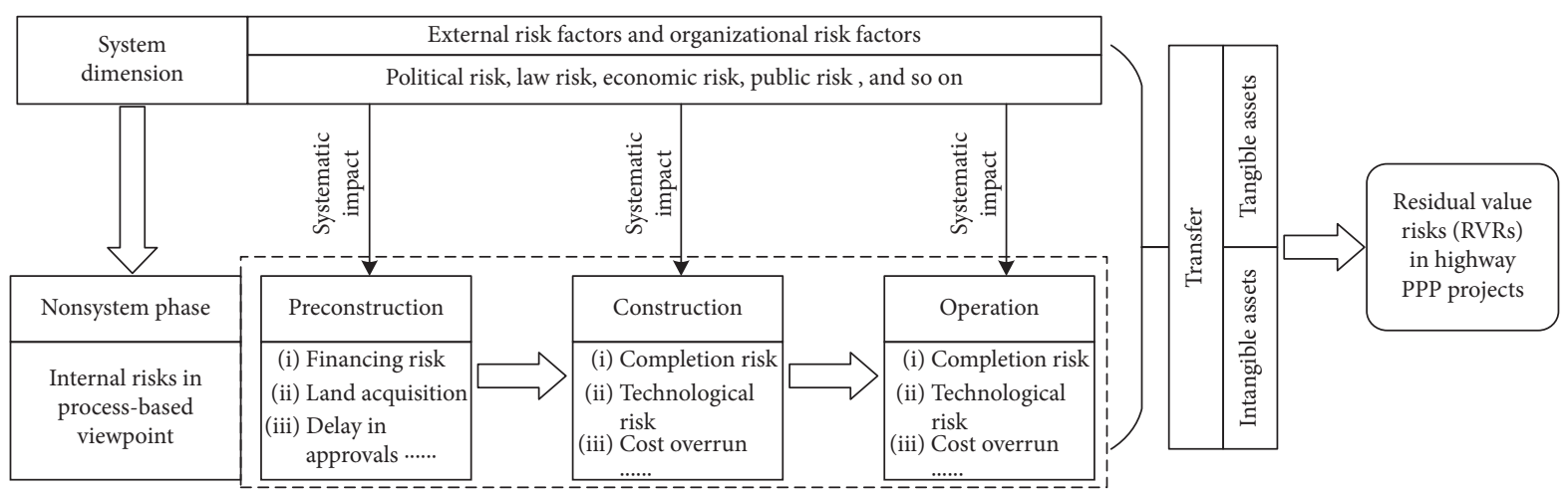

FIGURE 2: Conceptual model of RVR in highway PPP projects.

particular project activities. In preconstruction, specific factors involve with preparation work such as project planning, concessionaire selection, project finance, technology selection, and land acquirement, which cover the factors from F13 to F17. As for construction, "(F17) cost overrun," "(F18) schedule delay," "(F20) resource availability," and "F21 (quality risk)" are the risk factors of RVR in highway PPP. In operation, the risk factors are more concerned about the traffic flow, public services, and operation and maintenances (O\&M) than construction, including factors from F22 to F29. Since forecasting traffic volumes ex ante involves multiple factors such as expected economic growth, user behavior, price elasticity, and substitute or parallel facilities [77], many specific factors are related with demand variation in operation. Therefore, from the initiative to project transfer in a highway PPP project, the change of RV can be influenced by different factors in the three main stages, with an accumulative effect on the change of $\mathrm{RV}$ in project processes.

4.3. Hypothesized Relationships in the Conceptual Model. The conceptual model in Figure 2 is a representation for the RVR in highway PPP projects and serves as the foundation for exploring CRFs of RVR in highway PPP projects. The hypothesized relationships are as follows: (i) The system and nonsystem dimensions of RVR cover the specific risk factors from macrolevel to microlevel, which consist of the factor system of RVR in highway PPP projects completely. Moreover, the risk factors of system dimension exert influence on the risk factors of nonsystem dimension indirectly. (ii) The nonsystem dimension of RVR comprised three consecutive stages (including preconstruction, construction, and operation), and each stage consists of a number of underlying factors to reflect different impacts on RVR of highway PPP projects. All the risk factors have respective contributions to RVR of highway $\mathrm{PPP}$ projects in the corresponding stages. (iii) Since PPP putting design, build, finance, and operate contracts collectively, any risk factor of the three stages can generate critical influence on the change of RV in highway PPP projects, with accumulative effect during the full project cycle. Based on the above descriptions, this paper aims to validate the following hypothesis: (i) The classification of RVR in two dimensions and four categories is in accord with the internal relationships of RVR in highway PPP projects. (ii) The initial factor system gives an effective measurement of RVR in highway PPP projects. (iii) There is an accumulative effect of RVR in influencing the RV of highway PPP projects during the three stages. Therefore, the concluded hypotheses should reveal the CRFs of RVR systematically with validation from the survey data focusing on highway PPP projects around China.

\section{Survey Results and Analysis}

5.1. Descriptive Statistics. The profile of the respondents is presented in Table 2. The attendees can be classified by their experience in industry practice. Among 98 valid questionnaires, 56 respondents $(57.1 \%)$ were with more than ten years experiences in construction industry, and 98 (100\%) had experiences in highway PPP. Therefore, the selected sample survey can guarantee the credibility of survey. As for the sample size to variables ratio, it has been suggested with a range of 1.2 to up to 10 in the review conducted by Deng et al. [83]. Although most studies would recommend using sample sizes of at least 200 samples or 5-10 times greater than the number of survey questions [84], Sideridis et al. [85] found that a sample size of 50-70 would be enough for SEM/ CFA. Likewise, according to Xiong et al.'s [67] investigation of SEM application in construction research, 31.0\% (26 of 84 ) of models are derived from sample sizes less than 100 , and $85.7 \%$ (72 of 84 ) have a sample size to free parameters ratio less than 5. Moreover, the Hoelter value for default model in AMOS output is 93, which is lower than 98. The necessary sample size in fact depends on other conditions in addition to the sample size to variables ratio, including communality and the number of indicators per factor [83]. According to the review of SEM application conducted by Hair et al. [86], 100 samples are sufficient for most of the application as long as measurement is good (AVE $\geq 0.5$ or better). The received 98 valid questionnaires are without missing data because of face-to-face distribution approximately. Given all that, the questionnaire survey in this study involving 98 samples can meet the requirements of minimum sample size. The relevant evidences can be found in the following fit validity, convergent validity, and discriminant validity. 
TABle 2: Survey respondents' related experiences in industry.

\begin{tabular}{lcccc}
\hline Experiences & In construction industry & Percentage & In highway PPP & Percentage \\
\hline$\leq 5$ years & 10 & 10.20 & 39 & 39.79 \\
6-10 years & 32 & 32.65 & 26 & 18 \\
$11-15$ years & 24 & 24.49 & 13 & 18.37 \\
$16-20$ years & 18 & 18.37 & 2 & 13.27 \\
$\geq 21$ years & 14 & 14.29 & 98 & 2.04 \\
Total & 98 & 100.00 & 100.00 \\
\hline
\end{tabular}

5.2. Survey Evaluation. To further verify the reliability of the 98 valid surveys, Cronbach's $\alpha$ was used to test its internal consistency of the survey variable data. The reliability coefficient, Cronbach's $\alpha$, is generally used to test the reliability of scale [87]. The values of 0.70 or greater are considered as indicative of good scale reliability [88, 89]. As can be seen from the results of Table 3, Cronbach's $\alpha$ of the two dimension and four latent variables of proposed model range from 0.715 to 0.888 . These results suggested that the theoretical constructs exhibited good psychometric properties, which provided a basis for development of further analyses. Moreover, the surveyed factors were subjected to factor analysis using CFA. The Bartlett test of sphericity reflected that the associated significance level was 0.000 , indicating that the population correlation matrix is not an identity matrix. Additionally, the value of the Kaiser-Meyer-Olin (KMO) measure of sampling accuracy was 0.799 , which significantly exceeded 0.5 and thus was considered highly acceptable [76, 90]. Thus, the results of these tests showed that the sample data was appropriate for CFA.

5.3. MVA Analysis. Before conducting CFA, MVA analysis was conducted to identify the relative importance of the indicators and delete indicators with low importance subsequently. In this study, the mean scores, standard deviation, and distribution shape of collected data were chosen to identify the significant level and rank the indicators according to mean scores and standard deviation. The survey results are shown in Table 4. The mean values of the total 29 risk factors ranged from a maximum of 3.80 to a minimum of 2.80. The five most important indicators include "F10 (contract risk)," "F3 (government intervention)," "F15 (financial risk)," "F26 (market demand)," and "F12 (stakeholder risk)," with 3.80, 3.70, 3.77, 3.74, and 3.62, respectively. F10, the first ranking indicator from system dimension, includes the key clauses of risks and benefits arrangements between the public and private sectors. As for PPP contract, it is incomplete because of long-term uncertainty and complexity of contract structure. F3, the second ranking indicator from system dimension, reflects the specificity of PPP compared to traditional delivery in infrastructure development. The government is not only a participator but also a regulator in PPP projects. F15 is the third ranking indicator from preconstruction, which closely relates to affect capital expenditure and competitiveness of the private sector. F26, the fourth ranking indicator from operation, involves the difficulty in demand forecast during the long-term concession period. It is very important for
TABLE 3: Results of the reliability test.

\begin{tabular}{lccc}
\hline Dimensions of RVR & No. of items & \multicolumn{2}{c}{ Cronbach's alpha } \\
\hline System & 12 & \multicolumn{2}{c}{0.817} \\
Nonsystem & & \multicolumn{3}{c}{0.715} & \\
$\quad$ Preconstruction & 5 & 0.799 & 0.888 \\
$\quad$ Construction & 4 & 0.780 & \\
$\quad$ Operation & 8 & & \\
\hline
\end{tabular}

highway PPP projects because heavy capital investments depend on traffic income from expected traffic flow by userpay. F12 is another important indicator from system dimension, indicating that public welfare and private benefits should be well balanced for PPP success. However, not all indicators have strong impact on the RVR of highway PPP projects. Specifically, "F5 (foreign exchange)" and "F6 (inflation risk)" are lower than 3 , representing that they have less influence on the RVR. Overall, most factor mean values fell into the important ( $>3$ ) category, which denotes that the initial factor system can be used to measure the RVR in highway PPP projects. Meanwhile, the indicators with low importance should be further deleted in the following CFA analysis.

Regarding the values of skewness and kurtosis, Muthen and Kaplan [91] suggested that they should be close to zero, with an accepted value between +1.50 and -1.50 for normal distribution. In this study (Table 4), skewness values ranged from +0.195 for $\mathrm{F} 25$ to -1.030 for $\mathrm{F} 3$, and kurtosis values ranged from +0.102 for $\mathrm{F} 3$ to -1.214 for F13, meaning the survey data followed a relatively normal and symmetrical distribution. It could be concluded that these survey data could be used for further studies, including CFA and path analysis.

Furthermore, the difference of mean value for system dimension are rated 3.79-2.80, with the overall mean value of 3.375. By contrast, the difference of mean value for nonsystem dimension are rated 3.77-3.06, with the overall mean value of 3.383 . Therefore, the twelve factors of system dimension have more mean difference than that in nonsystem dimension, with 0.99 and 0.71 , respectively. This feature reveals that system RVR are more difficult to control than nonsystem RVR. Although China is the largest PPP market around the world, it is on the way to be a mature PPP market [10]. The development of PPP from 1984 to 2017 illustrates that external environment of PPP projects such as political, legal, and economic impacts should be heavily emphasized [11]. With respect to different stages of nonsystem dimension, the overall mean for preconstruction, construction, and operation are 3.454, 3.340, and 3.360, 
TABLE 4: Ranking and scores of factors for RVR in highway PPP projects.

\begin{tabular}{|c|c|c|c|c|c|c|}
\hline \multirow{2}{*}{ Risk dimension } & \multirow{2}{*}{ Items } & \multirow{2}{*}{ Mean } & \multirow{2}{*}{ Standard deviations } & \multirow{2}{*}{ Rank } & \multicolumn{2}{|c|}{ Distribution shape } \\
\hline & & & & & Skewness & Kurtosis \\
\hline \multirow{12}{*}{ System } & $\mathrm{F} 1$ & 3.56 & 1.362 & 6 & -0.585 & -0.930 \\
\hline & $\mathrm{F} 2$ & 3.35 & 1.049 & 18 & -0.149 & -0.736 \\
\hline & F3 & 3.79 & 1.235 & 2 & -1.030 & 0.102 \\
\hline & $\mathrm{F} 4$ & 3.21 & 1.018 & 22 & -0.075 & -0.692 \\
\hline & F5 & 2.80 & 1.130 & 29 & 0.145 & -0.657 \\
\hline & F6 & 2.99 & 1.121 & 28 & 0.111 & -0.885 \\
\hline & F7 & 3.37 & 1.167 & 16 & -0.330 & -0.751 \\
\hline & F8 & 3.48 & 1.133 & 9 & -0.513 & -0.310 \\
\hline & F9 & 3.14 & 1.207 & 25 & 0.128 & -0.866 \\
\hline & F10 & 3.80 & 1.087 & 1 & -0.661 & -0.269 \\
\hline & F11 & 3.39 & 0.944 & 13 & -0.471 & -0.113 \\
\hline & $\mathrm{F} 12$ & 3.62 & 0.981 & 5 & -0.183 & -0.940 \\
\hline \multicolumn{7}{|l|}{ Nonsystem } \\
\hline \multirow{5}{*}{ Preconstruction } & F13 & 3.38 & 1.298 & 14 & -0.246 & -1.214 \\
\hline & F14 & 3.55 & 1.158 & 7 & -0.626 & -0.419 \\
\hline & F15 & 3.77 & 1.221 & 3 & -0.958 & 0.010 \\
\hline & F16 & 3.36 & 1.079 & 17 & -0.424 & -0.387 \\
\hline & F17 & 3.21 & 1.021 & 23 & 0.094 & -0.551 \\
\hline \multirow{4}{*}{ Construction } & F18 & 3.32 & 1.145 & 20 & -0.222 & -0.712 \\
\hline & F19 & 3.46 & 1.151 & 10 & -0.355 & -0.736 \\
\hline & F20 & 3.06 & 1.008 & 27 & -0.125 & -0.467 \\
\hline & $\mathrm{F} 21$ & 3.52 & 1.133 & 8 & -0.399 & -0.562 \\
\hline \multirow{8}{*}{ Operation } & $\mathrm{F} 22$ & 3.40 & 1.101 & 12 & -0.232 & -0.719 \\
\hline & $\mathrm{F} 23$ & 3.33 & 0.911 & 19 & -0.015 & -0.645 \\
\hline & $\mathrm{F} 24$ & 3.31 & 0.873 & 21 & -0.563 & -0.191 \\
\hline & $\mathrm{F} 25$ & 3.10 & 1.079 & 26 & 0.195 & -0.561 \\
\hline & F26 & 3.74 & 1.143 & 4 & -0.582 & -0.476 \\
\hline & $\mathrm{F} 27$ & 3.37 & 1.046 & 15 & -0.294 & -0.479 \\
\hline & F28 & 3.45 & 1.142 & 11 & -0.531 & -0.273 \\
\hline & $\mathrm{F} 29$ & 3.18 & 0.960 & 24 & -0.177 & -0.157 \\
\hline
\end{tabular}

respectively, forming a smiling curve with the project progress. This feature reveals preconstruction and operation's key roles in RVR management of highway PPP projects. In preconstruction, feasibility assessment, VfM, and contract negotiation determine the key prerequisites for project success, whereas operation determines the project viability on economic, social, and environmental aspects [13]. Therefore, different risk factors in the three stages and two dimensions should be well managed with systematic and lifecycle management view.

\subsection{CFA Analysis}

5.4.1. Original CFA Model. Although the research survey indicated that most of the initial factors of RVR are important, similarity of the risk factors may result from the dependence of each empirical risk factor in specific category. In this case, CFA is a good approach for determining the covariation among the risk factors. A CFA was conducted by using AMOS 23.0 to test whether the proposed conceptual model fit the empirical data and further identified the important relationships between RVR and different factor clusters as well as between different factor and factor clusters. In this study, we choose maximum likelihood (ML) parameter estimation over other estimation methods because the data was basically distributed normally (Table 4) [92] and normal ML available in AMOS is robust to moderate violations of normality [67]. Based on the results of survey evaluation aforementioned, the survey data of this study are suitable for performing CFA.

As shown in Figure 3, the hypothesized measurement model includes endogenous observed variables (RVR), exogenous latent variables (dimensions, i.e., system and nonsystem), exogenous observed 29 variables (risk factors, i.e., F1, F2,..., F29), errors in the variables, and pathway coefficients (factor loadings). The latent variables that cannot be directly observed are measured with corresponding exogenous observed variables (indicators). The straight line from the latent variables (dimensions) to the corresponding observed variables indicates the causal effect on the observed variables (indicators). The factor loadings on the straight lines represent the relationship of indicators with their associated latent variables.

The loading coefficient of the 29 endogenous variables ranges from 0.30 to 0.86 and from 0.53 to 0.87 for the 4 latent variables. Thus, some of the standardized regression weights are not satisfactorily higher than 0.50 . Regarding the model validation, the original model obtained unsatisfactory results. The GFI is 0.780 (Table 5), and a cut-off point of 0.90 


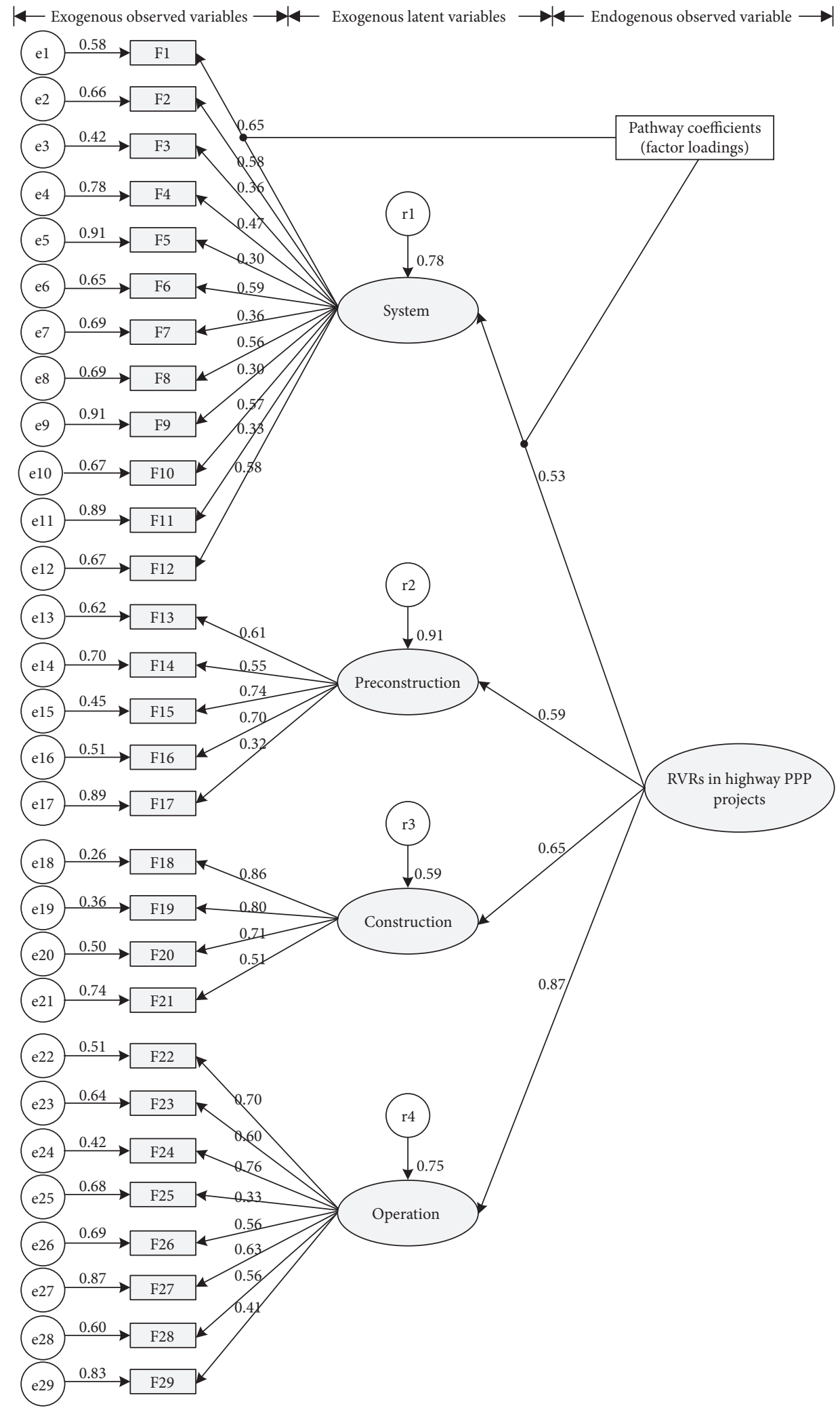

FIGURE 3: Original CFA model in measuring RVR of highway PPP projects.

has been recommended for the GFI [93]. $\chi^{2} / d f$ is 2.376, and the strict emulation criteria is lower than 2 [94]. Therefore, the original CFA model needed reasonable modification to increase its goodness of fit [95]. Considering the previously identified factors may be interdependent and lack of explanation power for the latent variables, those factors with relatively low loading coefficients and mean scores should be excluded in the revised model. 
TABLE 5: Validation assessment of the original measurement model.

\begin{tabular}{lccccccccc}
\hline Fit index & $\chi^{2} / d f(\mathrm{NC})$ & $P$ & RMSEA & GFI & TLI & IFI & CFI & PNFI & PGFI \\
\hline Measured values & 2.376 & $\leq 0.001$ & 0.058 & 0.780 & 0.898 & 0.922 & 0.918 & 0.602 & 0.741 \\
Acceptable level & $\mathrm{NC}<2$ & $<0.05$ & $<0.06$ & $>0.90$ & $>0.90$ & $>0.90$ & $>0.90$ & $>0.50$ & $>0.50$ \\
\hline
\end{tabular}

5.4.2. Improved CFA Model. To further improve the effectiveness of the proposed measurement model, the mean values obtained from MVA and factor loadings from CFA were both considered simultaneously to refine the CFA model in Figure 4. In this study, whose mean values were lower than 3.00 (F5 and F6) or factor loading were lower than 0.45 (F3, F5, F7, F9, F11, F17, F25, and F29) were excluded from the initial factor system. Then, the left factors were kept. Since F3 (government intervention) was identified as the CRFs in PPP $[63,65]$, this factor was kept. Therefore, 8 factors were excluded (F5, F6, F7, F9, F11, F17, F25, and F29), and 21 CRFs were identified finally. The reconstructed measurement model is shown in Figure 4. All the loading values of the observed variables exceed the cut-off value of 0.5 . In this case, the appropriate goodness of fit obtained satisfactory results is listed in Table 6.

Among these fit indices mentioned in Table 6, the value of RMSEA is equal to the cut-off level (0.06) and the value of GFI is little lower than the acceptable level. However, Browne and Cudeck [96] presented that the value of RMSEA smaller than 0.08 is also acceptable, and the value of GFI satisfies the constraints of $>0.80$ presented by Scott [97]. Overall, the results of measurement model demonstrated that the adequacy of the revised model was good enough according to the model's fit to the data. It is not necessary to take further modification.

5.4.3. Validity of Constructs. The revised CFA model (Figure 4) is used to assess how well the observed variables reflect unobserved or latent constructs for the RVR of highway PPP projects. Regarding CFA, construct validity is necessary for reliable model testing and theory development [67]. In this study, convergent validity and discriminant validity were used to validate the constructs proposed in the measurement model, which covers both "the degree of agreement of indicators hypothesized to measure a construct and the distinction between those indicators and indicators of a different construct(s)" [98].

Table 7 summarizes the relevant parameters in assessing convergent validity of the CFA model. Most of the loading coefficient exceeds 0.70 , and no one is lower than the cut-off level of 0.50 . The squared multiple correlations (analogous to $R^{2}$ ) are adequately large, ranging from 0.346 to 0.716 for the 21 factors and from 0.560 to 0.893 for the 4 latent constructs. Moreover, the composite reliability (CR) listed in the table are enough large, which meets the requirement of $\geq 0.70$ [86]. On the construct level, average variance extracted (AVE) is usually used to measure convergent validity and should be larger than 0.5 to indicate satisfactory convergent validity [99]. Thus, the values of AVE listed in the table show good convergent validity for each construct.
Table 8 illustrates the discriminant validity results for the revised CFA model. The lowest square root of the constructs is 0.72 , which is larger than the highest correlation between preconstruction and system (0.71). According to FornellLacker criteria [99], the square root of each construct's AVE should be larger than its highest correlations with other constructs. Therefore, the results indicate that the model achieves discriminant validity. Moreover, the higher correlation between system and nonsystem further verifies that system risk exerts significant influence on nonsystem risk for RVR in highway PPP projects, the higher correlation between the three consecutives stages implies that we should focus on the RVR development during the project processes.

\section{Discussions and Implications}

6.1. Discussion of Findings. Based on prior analyses, the proposed CFA model was examined with inherent relationships among the 21 identified CRFs of RVR under two dimensions and four categories. The associated explanation of the clustered CRFs is as follows. The mean scores and factor loading for the CRFs are listed in Table 9. Detailed analysis within four categories can be provided as follows.

6.1.1. Dimension of System. The seven out of the initial twelve CRFs (Table 9) refined from the revised measurement model (Figure 4) for system dimension are, in order of loading coefficient, F10, F3, F1, F2, F8, F12, and F4. They are related to the institutional environment (F1, F3, and F8), macroeconomy (F2 and F4), and relational aspect (F10 and F12). By observing the mean scores and loading coefficients of them, it is easily to find F10, F3, and F1 are the three most important factors of RVR in system dimension. All of them are in close relationship with government. As stressed by Wang [3], government intervention and public credit were the severe risk factors for successful PPP projects. The institutional environment for PPP in China is still far from mature $[10,48]$. In this case, imperfect laws and policy would encourage unreasonable intervention from government, which would reduce the private sector's cooperation confidence and increase the implementation costs with government. Thus, any implementation of PPP needs enabling legislation and policy to allow public entities to take advantages of the benefits of PPP project delivery while protecting the public welfare [30]. Among the mentioned CRFs in system dimension, PPP contract occupies a key position because it determines the risks/benefits allocation and respective roles among project participators based on local legal system and institutional framework. However, its incomplete property from asymmetric information among project participators and long-term uncertainty also needs credible endorsement from well-established and structured 


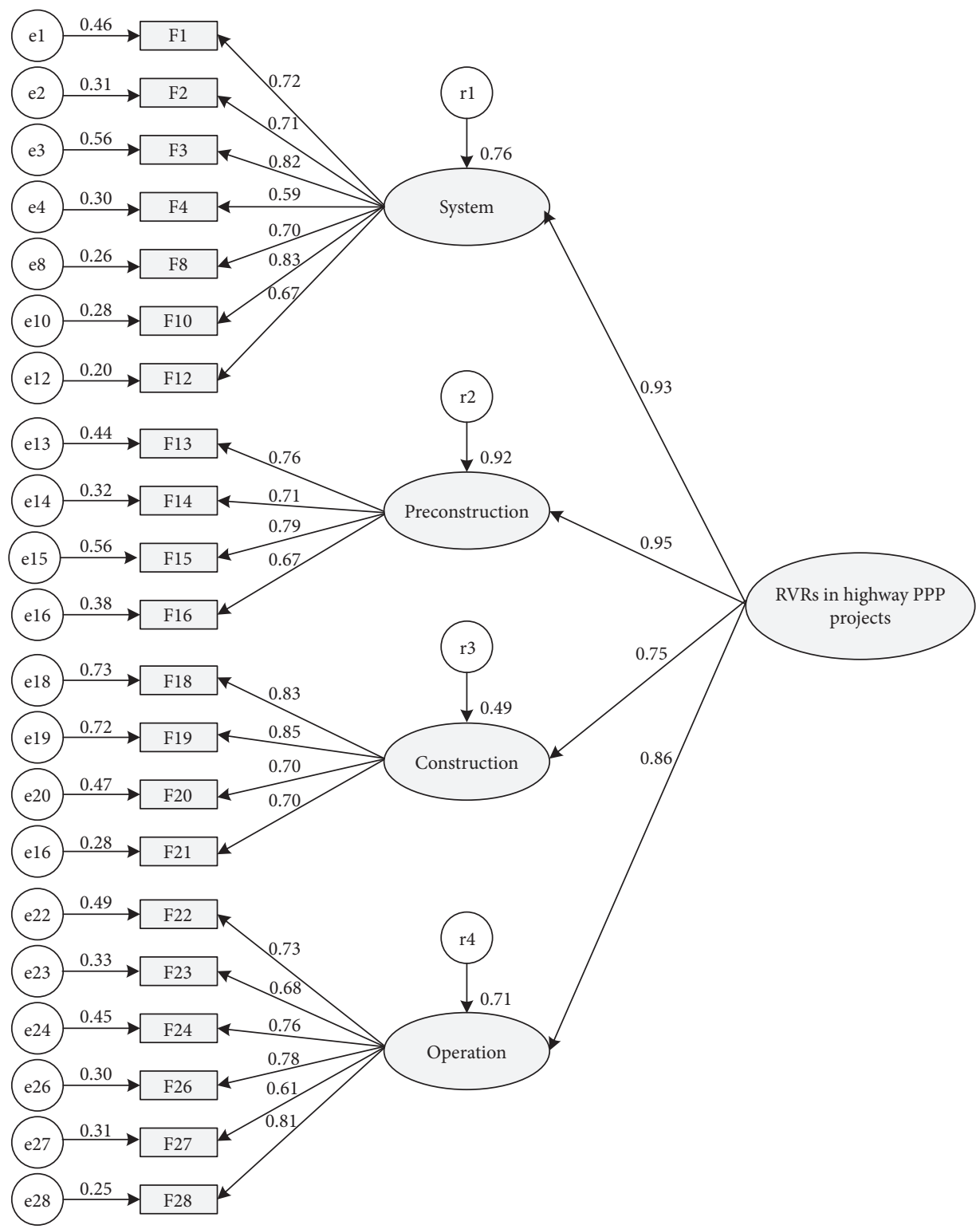

FIgURE 4: Revised CFA model in measuring RVR of highway PPP projects.

TABLE 6: Validation assessment of the revised measurement model.

\begin{tabular}{lccccccccc}
\hline Fit index & $\chi^{2} / d f(\mathrm{NC})$ & $P$ & RMSEA & GFI & TLI & IFI & CFI & PNFI & PGFI \\
\hline Measured values & 1.346 & 0.003 & 0.060 & 0.831 & 0.924 & 0.946 & 0.943 & 0.612 & 0.705 \\
Acceptable level & $\mathrm{NC}<2$ & $<0.05$ & $<0.06$ & $>0.90$ & $>0.90$ & $>0.90$ & $>0.90$ & $>0.50$ & $>0.50$ \\
\hline
\end{tabular}

legal system and policy framework. This is why F10 achieves the highest mean score and loading coefficient in system dimension. Moreover, stakeholder risk is another one important factor of relational aspects. Externally oriented management is very important to achieve satisfactory outcomes in dealing with stakeholder complexity in PPP [100]. Meanwhile, PPP contract can be viewed as the written and informal systems and procedures used for guidance and sometimes colloquially referred to projects as "following or going by the rule book" [101], providing basic principles for stakeholder management in the lifecycle of PPP. Thus, F10 and F12 can be viewed as relational consideration of RVR management, which should well reflect complex stakeholder's focus. Moreover, the factors of macroeconomy are also important in measuring RVR of highway PPP projects. Tax and interest are the two important tools for macroeconomic regulation and control. As a typical user-pay PPP, highway receives the early openness for private entity in China [6]. However, high initial investment and difficulty in full return indicate significant level of business risk and fiscal pressures [73]. As concluded by Mishra et al. [102] and Van et al. [68], interest fluctuation and tax change are critical in 
TABLE 7: Convergent validity analysis.

\begin{tabular}{|c|c|c|c|c|}
\hline Factors/categories & Loading coeff. & $R^{2}$ & $\mathrm{CR}$ & AVE \\
\hline F1 & 0.715 & 0.511 & \multirow{8}{*}{0.880} & \multirow{8}{*}{0.514} \\
\hline $\mathrm{F} 2$ & 0.706 & 0.498 & & \\
\hline F3 & 0.821 & 0.674 & & \\
\hline F4 & 0.588 & 0.346 & & \\
\hline F8 & 0.696 & 0.484 & & \\
\hline F10 & 0.826 & 0.682 & & \\
\hline $\mathrm{F} 12$ & 0.674 & 0.454 & & \\
\hline F13 & 0.759 & 0.576 & & \\
\hline F14 & 0.712 & 0.507 & \multirow{3}{*}{0.813} & \multirow{3}{*}{0.522} \\
\hline F15 & 0.785 & 0.616 & & \\
\hline F16 & 0.673 & 0.453 & & \\
\hline F18 & 0.825 & 0.681 & \multirow{5}{*}{0.845} & \multirow{4}{*}{0.579} \\
\hline F19 & 0.846 & 0.716 & & \\
\hline $\mathrm{F} 20$ & 0.704 & 0.496 & & \\
\hline $\mathrm{F} 21$ & 0.697 & 0.486 & & \\
\hline F22 & 0.732 & 0.536 & & \multirow{6}{*}{0.530} \\
\hline F23 & 0.675 & 0.456 & \multirow{5}{*}{0.870} & \\
\hline $\mathrm{F} 24$ & 0.756 & 0.572 & & \\
\hline F26 & 0.783 & 0.613 & & \\
\hline F27 & 0.614 & 0.377 & & \\
\hline F28 & 0.812 & 0.659 & & \\
\hline System & 0.932 & 0.869 & \multirow{4}{*}{0.928} & \multirow{4}{*}{0.764} \\
\hline Preconstruction & 0.945 & 0.893 & & \\
\hline Construction & 0.748 & 0.560 & & \\
\hline Operation & 0.857 & 0.734 & & \\
\hline
\end{tabular}

TABLE 8: Discriminant validity analysis.

\begin{tabular}{lccc}
\hline Latent construct & System & Preconstruction & Construction \\
\hline System & $\mathbf{0 . 7 2}$ & & \\
Preconstruction & 0.71 & $\mathbf{0 . 7 3}$ & $\mathbf{0 . 7 7}$ \\
Construction & 0.65 & 0.70 & 0.59 \\
Operation & 0.70 & 0.68 & $\mathbf{0 . 7 3}$ \\
\hline
\end{tabular}

Note. Data given in bold are the value of the square root of AVE.

influencing financial cost and payback period though economic analysis. Most importantly, they are determined by multiple factors from macrolevel and out of the control of project participators. Therefore, in order to control RVR from system dimension, it is necessary to attach more importance on institutional environment, macro economy, and relational aspects. Creating an environment that both attracts private investment and properly regulates PPP can be helpful to reduce macro uncertainty and extend the government's capacity in facilitating PPP implementation to improve RV, which make ease to start a highway PPP.

6.1.2. Period of Preconstruction. Preconstruction is the first period of nonsystem dimension on RVR of highway PPP projects. Four out of original five CRFs refined from the revised CFA model are, in order of loading coefficient, "F15 (financial risk)," "F13 (land acquisition)," "F14 (delayed approval)," and "F16 (design defects or delay)." Of these factors, F15 achieves the highest mean score (3.77) and explanation power (0.79) of RVR from preconstruction period. Infrastructure PPP is principally financial arrangements [77]. For highway PPP, some inherent feature such as high level of capital expenditure, difficulty of cost recovery, and long technical lifetime of facility maintenance makes it less attractive for the private entity. Therefore, joint financing by several consortiums in highway PPP is common, which is a challenge of the private sector's financial ability. Subsequently, the two important indicators F14 and F13 mainly involve with the private sector's efforts, which also need strong facilitation from the government. PPP as a public policy has a direct relation with political setting of the host country [63]. Without necessary political support, PPP project would not be approved timely and smoothly. By comparison, technical risks such as F16 have lower importance (3.36) and explanation power (0.67) for preconstruction period. Thus, the CRFs in preconstruction period are mainly related to poor public decision-making process because of the Chinese government's lack of knowledge in guiding PPP process and unrealistic guarantees [44]. However, the private business competence is still the critical determinant in completing these works with high quality and low costs. In this stage, many preparations such as project selection, project finance, design scheme, and construction technology should be well planned for subsequent construction and operation. Although inevitable 
TABLE 9: Means and loadings for CRFs of RVR in highway PPP projects.

\begin{tabular}{|c|c|c|c|c|c|c|c|}
\hline \multirow{3}{*}{ Categories } & \multirow{3}{*}{ Factors } & \multirow{2}{*}{\multicolumn{2}{|c|}{ MVA }} & \multicolumn{4}{|c|}{ CFA } \\
\hline & & & & \multicolumn{2}{|c|}{ Original model } & \multicolumn{2}{|c|}{ Revised model } \\
\hline & & Mean & Rank & Loading coeff. & Rank & Loading coeff. & Rank \\
\hline \multirow{12}{*}{ System } & $\mathrm{F} 1$ & 3.56 & 6 & 0.65 & 7 & 0.72 & 9 \\
\hline & $\mathrm{F} 2$ & 3.35 & 18 & 0.58 & 12 & 0.71 & 10 \\
\hline & F3 & 3.79 & 2 & 0.36 & 19 & 0.82 & 3 \\
\hline & $\mathrm{F} 4$ & 3.21 & 22 & 0.47 & 17 & 0.59 & 15 \\
\hline & F5 & 2.80 & 29 & 0.30 & 22 & - & - \\
\hline & F6 & 2.99 & 28 & 0.59 & 11 & - & - \\
\hline & F7 & 3.37 & 16 & 0.36 & 19 & - & - \\
\hline & F8 & 3.48 & 9 & 0.56 & 14 & 0.70 & 11 \\
\hline & F9 & 3.14 & 25 & 0.30 & 22 & - & - \\
\hline & F10 & 3.80 & 1 & 0.57 & 13 & 0.83 & 2 \\
\hline & F11 & 3.39 & 13 & 0.33 & 20 & - & - \\
\hline & $\mathrm{F} 12$ & 3.62 & 5 & 0.58 & 12 & 0.67 & 13 \\
\hline \multirow{5}{*}{ Preconstruction } & F13 & 3.38 & 14 & 0.61 & 9 & 0.76 & 7 \\
\hline & F14 & 3.55 & 7 & 0.55 & 15 & 0.71 & 10 \\
\hline & F15 & 3.77 & 3 & 0.74 & 4 & 0.79 & 5 \\
\hline & F16 & 3.36 & 17 & 0.70 & 6 & 0.67 & 13 \\
\hline & F17 & 3.21 & 23 & 0.32 & 21 & - & - \\
\hline \multirow{4}{*}{ Construction } & F18 & 3.32 & 20 & 0.86 & 1 & 0.83 & 2 \\
\hline & F19 & 3.46 & 10 & 0.80 & 2 & 0.85 & 1 \\
\hline & F20 & 3.06 & 27 & 0.71 & 5 & 0.70 & 11 \\
\hline & $\mathrm{F} 21$ & 3.52 & 8 & 0.51 & 16 & 0.70 & 11 \\
\hline \multirow{8}{*}{ Operation } & F22 & 3.40 & 12 & 0.70 & 6 & 0.73 & 8 \\
\hline & $\mathrm{F} 23$ & 3.33 & 19 & 0.60 & 10 & 0.68 & 12 \\
\hline & $\mathrm{F} 24$ & 3.31 & 21 & 0.76 & 3 & 0.76 & 7 \\
\hline & F25 & 3.10 & 26 & 0.33 & 20 & - & - \\
\hline & F26 & 3.74 & 4 & 0.56 & 14 & 0.78 & 6 \\
\hline & F27 & 3.37 & 15 & 0.63 & 8 & 0.61 & 14 \\
\hline & F28 & 3.45 & 11 & 0.56 & 14 & 0.81 & 4 \\
\hline & F29 & 3.18 & 24 & 0.41 & 18 & - & - \\
\hline
\end{tabular}

changes would occur because of future uncertainty, this stage establishes the basis for the whole project, especially the optimized design for constructability and operability. Overall, nontechnical risks and private-related risks play more important roles to affect RV of highway PPP projects during preconstruction period.

6.1.3. Period of Construction. Construction is the second period of nonsystem dimension on RVR of highway PPP projects. There is no factor deletion in this group, indicating that the four indicators can measure the RVR of construction well. Among these factors, "F21 (quality risk)" and "F19 (schedule delay)" obtain the highest importance (3.52) and explanation power (0.85) for RVR in construction period. In this stage, construction quality determines the input for future function of sustainable operation and a higher facility quality mean lower operation costs and longer operation period. Meanwhile, F19 is important because any delay in construction period mean a shortened operation period, which could result in the decrease of economic revenue, increase of costs, and dissatisfaction for the general public to further reduce the tangible and intangible RV of highway PPP projects. Subsequently, "F18 (cost overrun)" is also important in construction. Construction cost account for most of the total investment of highway PPP projects [8], with significant effect on fixed assets and price of toll in operation. Obviously, the conventional "iron-triangle" objectives are still important in RVR management in construction of highway PPP projects because time, cost, and quality are the commonly used indicators for assessing project performance according to project management perspective [21]. Moreover, "F20 (resource availability)" is another important indicator. As for highway PPP projects, substantial resources including manpower, physical material, and finance are invested to form the fixed assets in a short time relatively, which have critical impacts on the construction cost and facility quality. Therefore, the conventional "iron-triangle" objectives are still important in management of highway PPP projects, and they should be well implemented with lifecycle management consideration.

6.1.4. Period of Operation. Although operation is the last period of the concession period in highway PPP projects, it is the embodiment of project performance and RVR management in the prior stages. Six out of the original eight CRFs refined from the revised CFA model are, in order of loading coefficient, "F28 (change in toll)," "F26 (market demand)," "F24 (maintenance cost)," "F22 (operating cost)," "F23 (quality of service)," and "F27 (horizontal competition)." As concluded from prior work, operability and 
maintainability are the two important dimensions to measure RVR in PPP projects [16]. The identified important factor such as F22, F21, and F23 reflect the measurement on operability and maintainability, indicating they are important in RVR management of highway PPP projects. The market risk is often problematic in PPP arrangements since forecasting traffic volumes ex ante involves multiple factors such as expected economic growth, user behavior, price elasticity, and substitute or parallel facilities [77]. Thus, it is not surprising to see F26 achieve the highest mean value (3.74) in this period, followed by the related causes such as "change in toll (F28, 3.45)," "horizontal competition (F27, 3.37)," and "quality of service (F23, 3.33)." On one hand, it is vital to reduce costs in operation; on the other hand, operation income should be improved by good service and toll adjustment. Overall, operation performance and market risk should be attached more importance on RVR management of highway PPP projects, and the profitability in operation is critical for sustainable operation of highway PPP projects.

Furthermore, by observing the loading coefficients of the four latent constructs, it is easy to find that preconstruction obtains the highest loading coefficient of 0.95 , followed by system (0.93), operation (0.86), and construction (0.75). Therefore, the RVR of the highway PPP projects can be well explained from the four latent constructs. With respect to system RVR, they are dependent on many institutional and government-related risks from macrolevel, which are more difficult to control compared to nonsystem risks. However, it is important to note that they determine the external and macroenvironment for PPP promotion and implementation. Regarding nonsystem dimension, preconstruction and operation achieved a higher loading than construction, which forms the same nature of mean scores among the three consecutive stages. Compared to traditional delivery methods, preconstruction is more important for PPP success because strategical plan should be well done to face long-term uncertainty and sustainable operation. Moreover, values of PPP contract are further explored by transferring maintenance and operation risks of the constructed facilities to private sectors [103]. Thus, operation stage of highway PPP projects can reflect the accumulative effect of RVR in preconstruction and construction centrally [15]. Based on the process-based perspective, lifecycle management should be well incorporated in RVR management because of accumulative effect on RVR during the project processes, especially ex ante and ex post control.

6.2. Strategic Implications. $21 \mathrm{CRF}$ of RVR in highway PPP projects are extracted from the initial factor system according to the proposed conceptual model by MVA and CFA. Overall, the RVR of highway PPP projects strongly influenced by system dimension and nonsystem dimension, with an accumulative effect on the lifecycle of highway PPP projects. The identified CRFs and latent constructs provide effective measurement of RVR in highway PPP projects. The strategic implications of the findings can be summarized as follows: (i) The 21 identified CRFs of RVR in highway PPP projects can contribute to the knowledge body of RVR and RVR management. By discriminating system and nonsystem dimensions of RVR in highway PPP projects, the identified CRFs do not suggest that the occurrence of RVR is in relation to external factors and internal factors, but also imply that both public and private sectors are involved with RVR management. System RVR are exogenous from macrolevel during the lifecycle of PPP projects, which is more difficult to be controlled than projectrelated RVR from nonsystem dimension. Moreover, system RVR exerts critical influences on nonsystem RVR because they determine the external environment for project implementation. Considering that creating an environment that both attracts private investment and properly regulates PPP is fundamental to realize VfM [10], the public sector should emphasize on establishing conducive regulatory frameworks and effective institutions. Regarding to system RVR, institutional environment (F1, F3, and F8) and macroeconomy (F2 and F4) should be allocated to the public sectors because the public sector prefers to retain most political, legal, and social risks [40]. Among the system RVR, F10 (contract risk), along with F12 (stakeholder risk), indicates that RVR is a mutual-shared risk in PPP project. Moreover, as identified with high importance among RVR factors, PPP contract can act as a good indicator of the interactive relationships among RVR between system and nonsystem because it reflects the risk and benefit arrangements in the long-term concession period. By contrast, most of nonsystem RVRs are mainly related to project activities on the mesolevel, which is consistent to the risk allocation conducted by $\mathrm{Ke}$ et al. [40]. Unlike the traditional delivery system, the key feature of a PPP is that the assets or services provided are specified in terms of outputs rather than inputs [25]. This feature is evident in RVR development because many of nonsystem RVR factors are related with the private sector's expertise and efforts during the later stages. Among the nonsystem RVR factors, financial viability occupies significant importance across the project processes, examples can be found in F15 (financial risk), F19 (schedule delay), F24 (maintenance cost), and F28 (change in toll). Thus, financial viability is significant in RVR development because the balance between profit and sustainability can facilitate long-term partnerships and VfM [27]. Likewise, it is critical for the private sector to develop a good partnership with the public sector in managing the nonsystem RVR (especially during the preconstruction period) because the preparation to start PPP cannot be done well without government supports. Considering that the three stages related to nonsystem RVR are highly correlated with an accumulative effect on RVR development, both public and private sector should improve the processes and learn lessons during 
the long-term cooperation. Among them, preconstruction and operation should be attached more importance because they are the two critical stages in reducing RVR of highway PPP projects. Considering the high occurrence of renegotiations and early terminations of PPP projects [27], ex post RVR management should be strengthened because operation and maintenance is coming for more and more PPP projects. However, this does not mean that construction is not important in RVR management. As a transition stage, the "iron-triangle" objectives according to project management are still significant in controlling RVR in construction period because many sustainable objectives are derived from the "iron-triangle" objectives. Given all that, the public sector should bear the responsibility to attract private participation (especially macro and external RVR), while the private sector should try their best to control RVR with its expertise in the provision of assets and services (especially meso and internal RVR). Moreover, lifecycle management should be well incorporated into RVR management of highway PPP projects in case of the accumulative effect of RVR, with long-term collaboration among project stakeholders.

(ii) The 21 identified CRFs of RVR in highway PPP projects can provide useful tool to evaluate RVR as well as guidance for enterprise innovation in PPP practice. Compared to PPP, traditional procurement separates the construction phase from the sequent O\&M phase by only purchasing the construction service from the private firms, leading to insufficient O\&M and service deterioration in the long-term contract [2]. Therefore, many private companies have strong technology in construction but weak technology in project finance and operation in the long-term contract. As presented by Zhang and Soomro [20], there is a failure path among improper demand forecasting, low traffic demand, less revenue generation, and concessionaire insolvency for the private sector in transportation PPP projects. Therefore, the private sectors must strengthen their lifecycle capability through vertical and horizontal integration to adapt the popular application of PPP in highway projects or other sectors, with a transition from infrastructure contractor to infrastructure operator. Moreover, in order to reduce RVR in highway PPP projects, institutional environment, macroeconomy, and relational risks should be considered in preconstruction, while financial viability in preconstruction and operation should be highly emphasized for the private entity. Once PPP projects are up and running and producing income, hopefully all parties will become flexible in long-term cooperation. This will in turn expand the ability of the private sector to meet the government service requirements with hard work and innovative ideas [104]. Therefore, the explored nature of CRFs of RVR suggests that the private sectors should balance public welfare and private benefits as well as short-term benefits and long-term interests in highway PPP projects. To a large extent, CRFs are also the critical success factors for highway PPP projects. Considering that RVR is revenue-related and mutualshared during the processes of PPP project, the private sector should pay enough attention to RVR management through lifecycle management and long-term partnerships with the public sector.

\section{Conclusions}

With the PPP upsurge in China, more and more PPP projects will face the coming operation and transfer in the future. RVR has emerged as an important topic in Chinese PPP research and practice because of sustainability in PPP development and immature PPP market and institution in China. To this end, this study proposed a second-order CFA model consisting of system and nonsystem dimensions with 29 initial factors for measuring RVR in highway PPP projects. Based on empirical data collected by a nationwide investigation in China, the proposed CFA model was validated and 21 CRFs of RVR in highway PPP projects were identified through MVA and CFA.

Unlike prior studies in PPP risk, this study does not only provide a process-based perspective to understand PPP risk associated with RV, but also inspires the researchers and practitioners to pay attention to RVR and sustainability of PPP projects. Although Yuan et al. [16] defined RVR for PPP generally, validated the importance of RVR through case study [15], and identified the key indicators of RVRs through value-based viewpoint [24], they have not measured RVR in highway PPP projects from a process-based viewpoint. This study advances an in-depth understanding of RVR and supporting RVR management in typical PPP projects in China. The main contributions include, but are not limited to, the following:

(1) The validated model associated with CRFs of RVR can act as a base model for the comprehensive benchmark to evaluate RVR in highway PPP projects during the project processes.

(2) It discriminates RVR with conceptualized constructs from system and nonsystem dimension. The former is more difficult to be controlled than the latter with an accumulative effect during the three consecutive stages.

(3) The public sector should pay more attention on system RVR from macrolevel, while the private sector should attach more importance on nonsystem RVR from mesolevel, especially the RVR from preconstruction and operation.

(4) Lifecycle management should be incorporated in RVR management, and long-term partnerships retained between the public and private sector are beneficial to RVR management. 
Although this research can contribute to sustainable management of PPP projects for both researchers and project managers, three limitations should be mentioned for future work. Firstly, this study is aimed at investigating the CRFs of RVR for highway PPP projects in China. Regarding the limitation of investigation background, when it is used in other PPP projects such as government-pay project, "brownfield" projects, and social infrastructure projects, a few changes may occur in the relative importance of identified CRFs of RVR, depending on the project type, project location, and PPP maturity. Thus, it can act as a pilot study in measuring RVR and providing reference for RVR management in transportation PPP projects, in China or other countries. Secondly, RVR are developed during the long-term PPP contract under uncertainty. Thus, longitudinal study as well as dynamic analysis would be better to reveal the inherent mechanism of RVR development over time. Thirdly, some of the hypotheses need to be further validated though broader data, such as the cause-and-effect relationships among different risk dimensions and factors because of its interrelationships within dynamic environment.

\section{Data Availability}

The data used to support the findings of this study are included within the article.

\section{Disclosure}

The founding sponsors had no role in the design of the study; in the collection, analyses, or interpretation of data; in the writing of the manuscript; and in the decision to publish the results.

\section{Conflicts of Interest}

The authors declare no conflicts of interest.

\section{Acknowledgments}

This work was supported by the National Natural Science Foundation of China (nos. 71472037 and 71671042), the Fundamental Research Funds for the Central Universities of China and Postgraduates' Science and Innovation Foundation of Jiangsu Province (no. KYLX15_0096), and the Natural Science Research Program of Jiangsu Higher Education (18KJB560008).

\section{References}

[1] R. Macário, J. Ribeiro, and J. D. Costa, "Understanding pitfalls in the application of PPPs in transport infrastructure in Portugal,” Transport Policy, vol. 41, pp. 90-99, 2015.

[2] Z. Dong, M. Wang, and X. Yang, "Comparative study of China and USA public private partnerships in public transportation," Journal of Modern Transportation, vol. 24, no. 3, pp. 215-223, 2016.

[3] Y. Wang, "Evolution of public-private partnership models in American toll road development: learning based on public institutions' risk management," International Journal of Project Management, vol. 33, no. 3, pp. 684-696, 2015.

[4] Y. Shi, "Carrying out the spirits of the 19th National Congress of Communist Party of China fully and striving to create a new situation in PPP reform of China," 2017, http:// www.cpppf.com.cn/NewsDetail_587.html.

[5] J. Shaoul, A. Stafford, and P. Stapleton, "Highway robbery? A financial analysis of design, build, finance and operate (DBFO) in UK roads," Transport Reviews, vol. 26, no. 3, pp. 257-274, 2006.

[6] S. Zhang, Y. Gao, Z. Feng, and W. Sun, "PPP application in infrastructure development in China: institutional analysis and implications," International Journal of Project Management, vol. 33, no. 3, pp. 497-509, 2015.

[7] China Public Private Partnerships Center (CPPPC), "Report on the analysis of the third batch of pilot PPP projects," 2017, http://www.cpppc.org/zh/zyxmqd/4125.jhtml.

[8] Y. Xu, M. J. Skibniewski, Y. Zhang, A. P. C. Chan, and J. F. Y. Yeung, "Developing a concession pricing model for PPP highway projects," International Journal of Strategic Property Management, vol. 16, no. 2, pp. 201-217, 2012.

[9] R. Mu, M. D. Jong, and J. Koppenjan, "The rise and fall of public-private partnerships in China: a path-dependent approach," Journal of Transport Geography, vol. 19, no. 4, pp. 794-806, 2011.

[10] The Economist Intelligence Unit Ltd. and Asian Development Bank, "Evaluating the environment for public-private partnerships in Asia-Pacific," 2019, http://www.eiu.com/ Handlers/WhitepaperHandler.ashx?fi=Asia+Infrascope+2014ADB+report.pdf\&mode=wp\&campaignid=AsiaInfrascope2014.

[11] Beijing Bridata Technology Co., Ltd. and The International PPP Center of Southeast University, "Analysis on the development course and characteristics of China's PPP,” 2017, http://www.bridata.com/front/pdf/detail?id=1045.

[12] W. Xiong, X. Zhao, J.-F. Yuan, and S. Luo, "Ex post risk management in Public-Private Partnership infrastructure projects," Project Management Journal, vol. 48, no. 3, pp. 76-89, 2017.

[13] M. A. Soomro and X. Zhang, "Evaluation of the functions of public sector partners in transportation public-private partnerships failures," Journal of Management in Engineering, vol. 32, no. 1, article 04015027, 2016.

[14] M. A. Soomro and X. Zhang, "Roles of private-sector partners in transportation public-private partnership failures," Journal of Management in Engineering, vol. 31, no. 4, article 04014056, 2015.

[15] J. Yuan, A. P. C. Chan, B. Xia et al., "Cumulative effects on the change of residual value in PPP projects: a comparative case study," Journal of Infrastructure Systems, vol. 22, no. 2, article 05015006, 2016.

[16] J. Yuan, A. P. C. Chan, W. Xiong et al., "Perception of residual value risk in public private partnership projects: critical review," Journal of Management in Engineering, vol. 31, no. 3, article 04014041, 2015.

[17] Private Finance Panel, Risk and Reward in PFI Contracts: Practical Guidance on the Sharing of Risk and the Structuring of PFI Contracts, Private Finance Panel, London, UK, 1996.

[18] J. Hall, "Private opportunity, public benefit?," Fiscal Studies, vol. 19, no. 2, pp. 121-140, 1998.

[19] X.-H. Jin, "Determinants of efficient risk allocation in privately financed public infrastructure projects in Australia," Journal of Construction Engineering and Management, vol. 136, no. 2, pp. 138-150, 2010. 
[20] X. Zhang and M. A. Soomro, "Failure path analysis with respect to private sector partners in transportation PublicPrivate Partnerships," Journal of Management in Engineering, vol. 32, no. 1, article 04015031, 2016.

[21] F. Villalba-Romero, C. Liyanage, and A. Roumboutsos, "Sustainable PPPs: a comparative approach for road infrastructure," Case Studies on Transport Policy, vol. 3, no. 2, pp. 243-250, 2015.

[22] HM Treasury of UK, "Standardisation of PFI contracts version 4," 2016, http://webarchive.nationalarchive.s.gov. uk/20130410173120, http://hm-treasury.gov.uk/d/pfi_ sopc4pu101_210307.pdf.

[23] Comptroller and Auditor General of India, "Public private partner-ships (PPP) in infrastructure projects: public auditing guideline," 2016, http://infrastructure.gov.in/pdf/ PPP-PROJECT.pdf.

[24] J. Yuan, W. Xu, B. Xia et al., "Exploring key indicators of residual value risks in China's Public-Private Partnership Projects," Journal of Management in Engineering, vol. 34, no. 1, article 04017046, 2018.

[25] World Bank Group, Asian Development Bank, and InterAmerican Development, "Public-private partnerships reference guide (version 3)," 2018, https://openknowledge. worldbank.org/handle/10986/20118.

[26] J. Song, H. Zhang, and W. Dong, "A review of emerging trends in global PPP research: analysis and visualization," Scientometrics, vol. 107, no. 3, pp. 1111-1147, 2016.

[27] J. F. M. Koppenjan and B. Enserink, "Public-Private Partnerships in urban infrastructures: reconciling private sector participation and sustainability," Public Administration Review, vol. 69, no. 2, pp. 284-296, 2009.

[28] Z. Lu and Q. Meng, "Analysis of optimal BOT highway capacity and economic toll adjustment provisions under traffic demand uncertainty," Transportation Research Part E: Logistics and Transportation Review, vol. 100, pp. 17-37, 2017.

[29] T. Liu, M. Bennon, M. J. Garvin et al., "Sharing the big risk: assessment framework for revenue risk sharing mechanisms in transportation public-private partnerships," Journal of Construction Engineering and Management, vol. 143, no. 12, article 04017086, 2017.

[30] P. Decorla-Souza, J. Mayer, A. Jette, and J. Buxbaum, "Key considerations for states seeking to implement public-private partnerships for new highway capacity," Transportation Research Record: Journal of the Transportation Research Board, vol. 2346, no. 1, pp. 23-31, 2013.

[31] C.-Y. Chang and S. Chen, "Transitional public-private partnership model in China: contracting with little recourse to contracts," Journal of Construction Engineering and Management, vol. 142, no. 10, article 05016011, 2016.

[32] Sate Council of China, "Opinions on strengthening the administration of local government debt," 2016, http://www. gov.cn/zhengce/content/2014-10/02/content_9111.htm.

[33] T. Liu, Y. Wang, and S. Wilkinson, "Identifying critical factors affecting the effectiveness and efficiency of tendering processes in public-private partnerships (PPPs): a comparative analysis of Australia and China," International Journal of Project Management, vol. 34, no. 4, pp. 701-716, 2016.

[34] Infrastructure Australia, "National PPP guidelines volume 4: public sector comparator guidance," 2016, http://www. infrastructureaustralia.gov.au/public_private/files/National_ PPP_GuidelinesVol_4_PSC_Guidance_Dec_08.pdf.

[35] Y. Xu, J. F. Y. Yeung, A. P. C. Chan, D. W. M. Chan, S. Q. Wang, and Y. Ke, "Developing a risk assessment model for PPP projects in China-a fuzzy synthetic evaluation approach," Automation in Construction, vol. 19, no. 7, pp. 929-943, 2010.

[36] R. Burke and I. Demirag, "Risk transfer and stakeholder relationships in public private partnerships," Accounting Forum, vol. 41, no. 1, pp. 28-43, 2017.

[37] A. P. C. Chan, J. F. Y. Yeung, C. C. P. Yu, S. Q. Wang, and Y. Ke, "Empirical study of risk assessment and allocation of public-private partnership projects in China," Journal of Management in Engineering, vol. 27, no. 3, pp. 136-148, 2011.

[38] J.-S. Chou, H. Ping Tserng, C. Lin, and C.-P. Yeh, "Critical factors and risk allocation for PPP policy: comparison between HSR and general infrastructure projects," Transport Policy, vol. 22, pp. 36-48, 2012.

[39] A. Valipour, N. Yahaya, N. Md Noor, S. Kildienè, H. Sarvari, and A. Mardani, "A fuzzy analytic network process method for risk prioritization in freeway PPP projects: an Iranian case study," Journal of Civil Engineering and Management, vol. 21, no. 7, pp. 933-947, 2015.

[40] Y. Ke, S. Wang, and A. P. C. Chan, "Risk allocation in publicprivate partnership infrastructure projects: comparative study," Journal of Infrastructure Systems, vol. 16, no. 4, pp. 343-351, 2010.

[41] S. Q. Wang, R. L. K. Tiong, S. K. Ting, and D. Ashley, "Evaluation and management of political risks in China's BOT projects," Journal of Construction Engineering and Management, vol. 126, no. 3, pp. 242-250, 2000.

[42] T. Sachs, R. Tiong, and S. Qing Wang, "Analysis of political risks and opportunities in public private partnerships (PPP) in China and selected Asian countries," Chinese Management Studies, vol. 1, no. 2, pp. 126-148, 2007.

[43] L.-Y. Shen, A. Platten, and X. P. Deng, "Role of public private partnerships to manage risks in public sector projects in Hong Kong," International Journal of Project Management, vol. 24, no. 7, pp. 587-594, 2006.

[44] E. Cheung and A. P. C. Chan, "Risk factors of public-private partnership projects in China: comparison between the water, power, and transportation sectors," Journal of Urban Planning and Development, vol. 137, no. 4, pp. 409-415, 2011.

[45] J. Song, D. Song, X. Zhang, and Y. Sun, "Risk identification for PPP waste-to-energy incineration projects in China," Energy Policy, vol. 61, pp. 953-962, 2013.

[46] A. P. C. Chan, P. T. I. Lam, Y. Wen et al., "Cross-sectional analysis of critical risk factors for PPP water projects in China," Journal of Infrastructure Systems, vol. 21, no. 1, article 04014031, 2015.

[47] Y. Xu, A. P. C. Chan, B. Xia, Q. K. Qian, Y. Liu, and Y. Peng, "Critical risk factors affecting the implementation of PPP waste-to-energy projects in China," Applied Energy, vol. 158, pp. 403-411, 2015.

[48] S. Zhang, A. P. C. Chan, Y. Feng, H. Duan, and Y. Ke, "Critical review on PPP research-a search from the Chinese and international journals," International Journal of Project Management, vol. 34, no. 4, pp. 597-612, 2016.

[49] J. Froud, "The private finance initiative," Accounting, Organizations and Society, vol. 28, no. 6, pp. 567-589, 2003.

[50] X.-H. Jin and G. Zhang, "Modelling optimal risk allocation in PPP projects using artificial neural networks," International Journal of Project Management, vol. 29, no. 5, pp. 591-603, 2011.

[51] G. Roberts, "Long term thinking," Highways, vol. 72, no. 2, pp. 16-19, 2003.

[52] I. Demirag, I. Khadaroo, P. Stapleton, and C. Stevenson, "Risks and the financing of PPP: perspectives from the 
financiers," British Accounting Review, vol. 43, no. 4, pp. 294-310, 2011.

[53] A. M. Algarni, D. Arditi, and G. Polat, "Build-operatetransfer in infrastructure projects in the United States," Journal of Construction Engineering and Management, vol. 133, no. 10, pp. 728-735, 2007.

[54] B. Li, A. Akintoye, P. J. Edwards et al., "The allocation of risk in PPP/PFI construction projects in the UK," International Journal of Project Management, vol. 23, no. 5, pp. 459-471, 2005.

[55] N. A. Krüger, "To kill a real option-incomplete contracts, real options and PPP," Transportation Research Part A: Policy and Practice, vol. 46, no. 8, pp. 1359-1371, 2012.

[56] E. E. Ameyaw and A. P. C. Chan, "Evaluation and ranking of risk factors in public-private partnership water supply projects in developing countries using fuzzy synthetic evaluation approach," Expert Systems with Applications, vol. 42 , no. 12, pp. 5102-5116, 2015.

[57] M. S. Beasley, B. C. Branson, and B. V. Hancock, "How key risk indicators can sharpen focus on emerging risks," 2017, https://www.coso.org/Pages/default.aspx.

[58] J. Fraser and B. J. Simkins, Enterprise Risk Management: Today's Leading Research and Best Practices for Tomorrow Executives, John Wiley\& Sons, Hoboken, NJ, USA, 2011.

[59] X. Zhang, "Social risks for international players in the construction market: a China study," Habitat International, vol. 35, no. 3, pp. 514-519, 2011.

[60] X. Huang, H. Zhou, and H. Zhu, "Assessing the systemic risk of a heterogeneous portfolio of banks during the recent financial crisis," Journal of Financial Stability, vol. 8, no. 3, pp. 193-205, 2012.

[61] I. Heckmann, T. Comes, and S. Nickel, "A critical review on supply chain risk-definition, measure and modeling," Omega, vol. 52, pp. 119-132, 2015.

[62] C. Juan, F. Olmos, and E. Pérez, "Decision support system to design feasible high-frequency motorways of the sea: a new perspective for public commitment," Engineering Economist, vol. 61, no. 3, pp. 163-189, 2016.

[63] B. Li, A. Akintoye, P. J. Edwards, and C. Hardcastle, "Critical success factors for PPP/PFI projects in the UK construction industry," Construction Management and Economics, vol. 23, no. 5, pp. 459-471, 2005.

[64] A. P. C. Chan, P. T. I. Lam, D. W. M. Chan, E. Cheung, and Y. Ke, "Drivers for adopting public private partnershipsempirical comparison between China and Hong Kong special administrative region," Journal of Construction Engineering and Management, vol. 135, no. 11, pp. 1115-1124, 2009.

[65] Y. Ke, S. Wang, A. P. C. Chan, and P. T. I. Lam, "Preferred risk allocation in China's public-private partnership (PPP) projects," International Journal of Project Management, vol. 28, no. 5, pp. 482-492, 2010.

[66] J. B. Schreiber, A. Nora, F. K. Stage, E. A. Barlow, and J. King, "Reporting structural equation modeling and confirmatory factor analysis results: a review," Journal of Educational Research, vol. 99, no. 6, pp. 323-338, 2006.

[67] B. Xiong, M. Skitmore, and B. Xia, "A critical review of structural equation modeling applications in construction research," Automation in Construction, vol. 49, pp. 59-70, 2015.

[68] H. Van, F. Wouter, E. Van et al., "Private financing of road taxation," in Proceedings of International Federation for Information Processing Working Group 8.5 Joint Conference on Electronic Government (EGOV) and Electronic
Participation (ePart), vol. 21, pp. 185-194, Dublin, Ireland, UK, 2014.

[69] E. E. Ameyaw and A. P. C. Chan, "Evaluating key risk factors for PPP water projects in Ghana: a Delphi study," Journal of Facilities Management, vol. 13, no. 2, pp. 133-155, 2015.

[70] R. Alasad and I. Motawa, "Dynamic demand risk assessment for toll road projects," Construction Management and Economics, vol. 33, no. 10, pp. 799-817, 2015.

[71] A. A. Aziz and T. Shen, "Management of force majeure risks in Canadian PPP transportation projects," in Proceedings of Construction Research Congress 2016, pp. 538-548, San Juan, Puerto Rico, 2016.

[72] S. Verweij, "Achieving satisfaction when implementing PPP transportation infrastructure projects: a qualitative comparative analysis of the A15 highway DBFM project," International Journal of Project Management, vol. 33, no. 1, pp. 189-200, 2015.

[73] V. Khmel and S. Zhao, "Arrangement of financing for highway infrastructure projects under the conditions of public-private partnership," IATSS Research, vol. 39, no. 2, pp. 138-145, 2016.

[74] P. C. Anastasopoulos, J. E. Haddock, and S. Peeta, "Cost overrun in public-private partnerships: toward sustainable highway maintenance and rehabilitation," Journal of Construction Engineering and Management, vol. 140, no. 6, article 04014018, 2014

[75] Y. Xu, C. Sun, M. J. Skibniewski, A. P. C. Chan, J. F. Y. Yeung, and H. Cheng, "System dynamics (SD)-based concession pricing model for PPP highway projects," International Journal of Project Management, vol. 30, no. 2, pp. 240-251, 2012.

[76] X. Zhang, "Factor analysis of public clients' best-value objective in public-privately partnered infrastructure projects," Journal of Construction Engineering and Management, vol. 132, no. 9, pp. 956-965, 2006.

[77] M. J. Garvin, "Enabling development of the transportation public-private partnership market in the United States," Journal of Construction Engineering and Management, vol. 136, no. 4, pp. 402-411, 2010.

[78] Engineering News-Record (ENR), “ENR's 2018 Top 250 International Contractors 1-100," 2019, https://www.enr. com/toplists/2018-Top-250-International-Contractors-1.

[79] M. Chen and X. J. Shi, "Risk allocation of Public-Private Partnerships in public stadium construction projects," in Proceedings of International Symposium on Advancement of Construction Management and Real Estate, vol. 1-6, pp. 1338-1342, Beijing, China, 2009.

[80] M. Frilet, "Some universal issues in BOT projects for public infrastructure," International Construction Law Review, vol. 14, no. 4, pp. 499-512, 1997.

[81] N. Pongsiri, Regulation and Public-Private Partnerships. Centre on Regulation and Competition, Institute for Development Policy, University of Manchester, Manchester, UK, 2001.

[82] Y. Wang, Public-Private Partnerships in the Social Sector: Issues and Country Experiences in Asia and the Pacific, Asian Development Bank Institute (ADBI) Publishing, Tokyo, Japan, 2000.

[83] L. Deng, M. Yang, and K. M. Marcoulides, "Structural equation modeling with many variables: a systematic review of issues and developments," Frontiers in Psychology, vol. 9, pp. 1-14, 2018.

[84] E. J. Wolf, K. M. Harrington, S. L. Clark, and M. W. Miller, "Sample size requirements for structural equation models," 
Educational and Psychological Measurement, vol. 73, no. 6, pp. 913-934, 2013.

[85] G. Sideridis, P. Simos, A. Papanicolaou, and J. Fletcher, "Using structural equation modeling to assess functional connectivity in the brain," Educational and Psychological Measurement, vol. 74, no. 5, pp. 733-758, 2014.

[86] J. F. Hair, B. J. Babin, and N. Krey, "Covariance-based structural equation modeling in the journal of advertising: review and recommendations," Journal of Advertising, vol. 46, no. 1, pp. 163-177, 2017.

[87] L. J. Cronbach, "Coefficient alpha and the internal structure of tests," Psychometrika, vol. 16, no. 3, pp. 297-334, 1951.

[88] S. W. O'Leary-Kelly and R. J. Vokurka, "The empirical assessment of construct validity," Journal of Operations Management, vol. 16, no. 4, pp. 387-405, 1998.

[89] L. R. Gay and P. W. Airasian, Educational Research: Competencies for Analysis and Application, Merrill, Upper Saddle River, NJ, USA, 2000.

[90] N. A. Pett, N. R. Lackey, and J. J. Sullivan, Making Sense of Factor Analysis: The Use of Factor Analysis for Instrument Development in Health Care Research, Sage Publications Inc., Thousand Oaks, CA, USA, 2003.

[91] B. Muthen and D. Kaplan, "A comparison of some methodologies for the factor analysis of non-normal Likert variables: a note on the size of the model," British Journal of Mathematical and Statistical Psychology, vol. 45, no. 1, pp. 19-30, 1992.

[92] R. B. Kline, Principles and Practice of Structural Equation Modeling, The Guilford Press Inc., New York, NY, USA, 2nd edition, 2005.

[93] M. Shevlin and J. N. V. Miles, "Effects of sample size, model specification and factor loadings on the GFI in confirmatory factor analysis," Personality and Individual Differences, vol. 25, no. 1, pp. 85-90, 1998.

[94] H. W. Marsh and K.-T. Hau, "Assessing goodness of fit," Journal of Experimental Education, vol. 64, no. 4, pp. 364390, 1996.

[95] J. F. Hair, W. C. Black, B. J. Babin et al., Multivariatre Data Analysis, Pearson Education International, London, UK, 6th edition, 2006.

[96] M. W. Browne and R. Cudeck, Alternative Ways of Assessing Model Fit, Sage Publications, Thousand Oaks, CA, USA, 1993.

[97] J. E. Scott, "The measurement of information system effectiveness: evaluation a measuring instrument," in Proceedings of the Fifteenth International Conference on Information System, pp. 111-128, Vancourver, BC, Canada, 1994.

[98] R. P. Bagozzi and Y. Yi, "Specification, evaluation, and interpretation of structural equation models," Journal of the Academy of Marketing Science, vol. 40, no. 1, pp. 8-34, 2012.

[99] R. P. Bagozzi, "Evaluating structural equation models with unobservable variables and measurement error: a comment," Journal of Marketing Research, vol. 18, no. 3, pp. 375-381, 1981.

[100] S. Verweij, "Producing satisfactory outcomes in the implementation phase of PPP infrastructure projects: a fuzzy set qualitative comparative analysis of 27 road constructions in The Netherlands," International Journal of Project Management, vol. 33, no. 8, pp. 1877-1887, 2015.

[101] A. J. Edkins and H. J. Smyth, "Contractual management in PPP projects: evaluation of legal versus relational contracting for service delivery," Journal of Professional Issues in
Engineering Education and Practice, vol. 132, no. 1, pp. 8293, 2006.

[102] S. Mishra, S. Khasnabis, and S. L. Dhingra, "A simulation approach for estimating value at risk in transportation infrastructure investment decisions," Research in Transportation Economics, vol. 38, no. 1, pp. 128-138, 2013.

[103] X. Zhang, "Public clients' best value perspectives of public private partnerships in infrastructure development," Journal of Construction Engineering and Management, vol. 132, no. 2, pp. 107-114, 2006.

[104] M. Tiffin and P. Hall, "PFI- the last chance saloon?," Proceedings of the Institution of Civil Engineers-Civil Engineering, vol. 126, no. 1, pp. 12-18, 1998. 


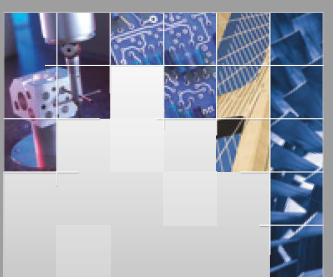

\section{Enfincering}
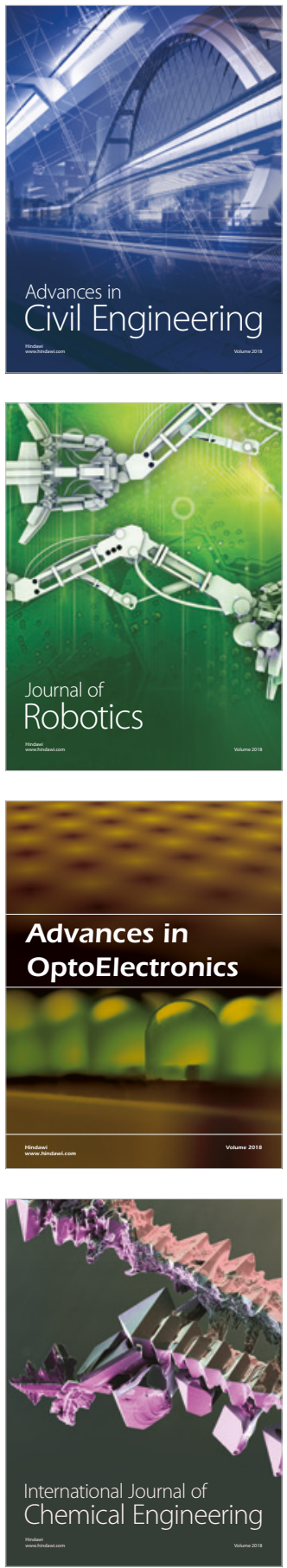

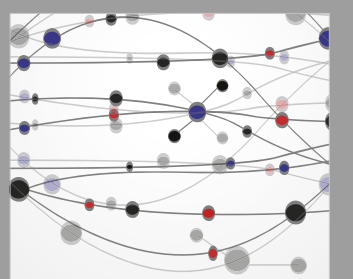

\section{Rotating \\ Machinery}

The Scientific World Journal

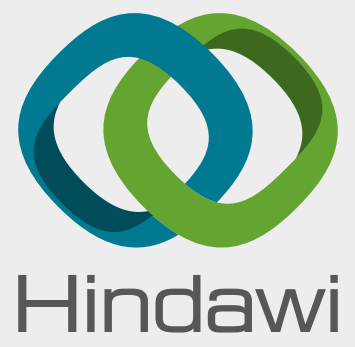

Submit your manuscripts at

www.hindawi.com
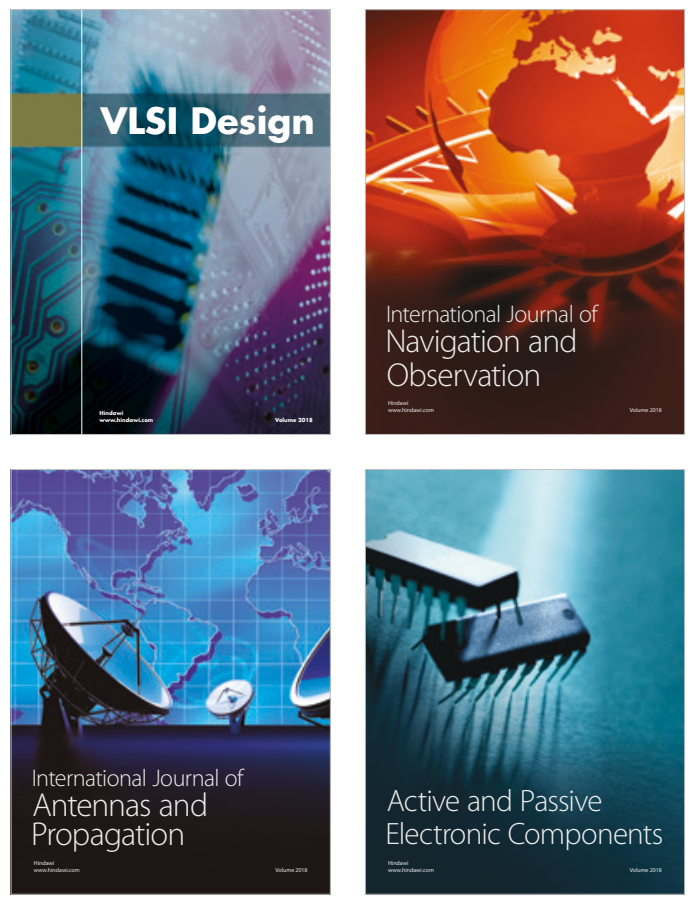
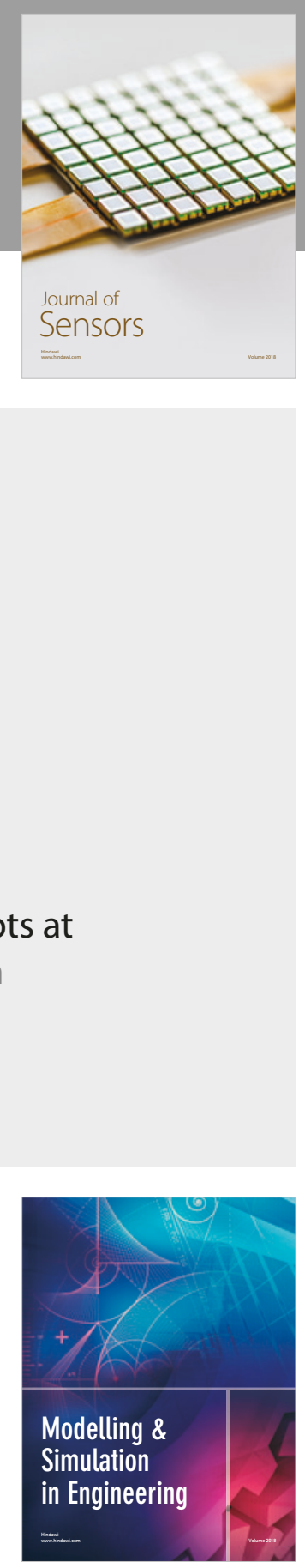

\section{Advances \\ Multimedia}
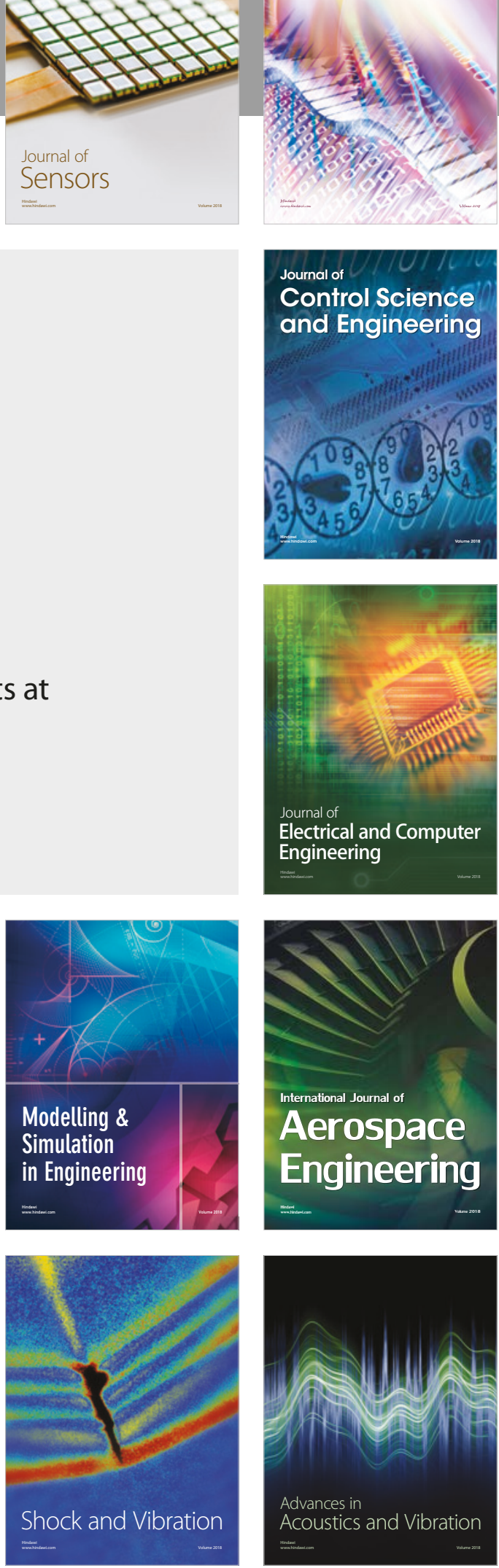